Running head: Left-Wing Authoritarianism

\title{
Is the Myth of Left-Wing Authoritarianism Itself a Myth?
}

\author{
Lucian Gideon Conway, III \\ Alivia Zubrod \\ Linus Chan \\ James D. McFarland \\ The University of Montana \\ Evert Van de Vliert \\ University of Groningen
}

Corresponding Author:

Lucian Gideon Conway, III,

Professor, Psychology Department

University of Montana

Missoula, MT 59812

Luke.conway@umontana.edu

This working paper has not yet been peer-reviewed. Date: December 18, 2020 


\begin{abstract}
Is left-wing authoritarianism (LWA) closer to a myth or a reality? Twelve studies test the empirical existence and theoretical relevance of LWA. Study 1 reveals that both conservative and liberal Americans identify a large number of left-wing authoritarians in their lives. In Study 2, participants explicitly rate items from a recently-developed LWA measure as valid measurements of authoritarianism. Studies 3-11 show that persons who score high on this same LWA scale possess the traits associated with models of authoritarianism (while controlling for political ideology): LWA is positively related to threat sensitivity across multiple areas, including general ecological threats (Study 3), COVID disease threat (Study 4), Belief in a Dangerous World (Study 5), and Trump threat (Study 6). Further, controlling for ideology, high-LWA persons show more support for restrictive political correctness norms (Study 7), rate African-Americans and Jews more negatively (Studies 8-9), and show more domain-specific dogmatism and attitude strength (Study 10). Study 11 reveals that the majority of the effects from Studies 3-10 hold when looking only within liberals, thus revealing these effects are about liberal authoritarianism. Study 12 uses the World Values Survey to provide evidence of LeftWing Authoritarianism around the globe. Taken in total, this large array of triangulating evidence from 12 studies comprised of over 8,000 participants from the U.S. and over 66,000 participants world-wide strongly suggests that left-wing authoritarianism is much closer to a reality than a myth.
\end{abstract}




\section{Is the Myth of Left-Wing Authoritarianism Itself a Myth?}

The idea that liberals can show rigid adherence to authority figures - known as left-wing authoritarianism (LWA) - has a rocky history in psychology. Indeed, some scholars have expressed extreme skepticism about the validity or real-life viability of the construct, with researchers calling it a myth on par with the Loch Ness Monster, or suggesting that left-wing authoritarian persons are as rare as hen's teeth (Altemeyer, 1996; Jost et al., 2003; Stone, 1980).

However, others have historically argued that left-wing authoritarianism is a relevant reality deserving of scientific attention (e.g., Eysenck, 1954; McFarland et al., 1996; Mullen et al., 2003; Ray, 1983; Rokeach, 1960; Shils, 1954; Van Hiel et al., 2006). Burgeoning evidence spanning multiple nations, independent research programs, and cultural contexts suggests that LWA exists and has important consequences (Conway et al., 2018; Conway \& McFarland, 2019; Conway et al., in press; Costello et al., 2020; De Regt et al.2011; Fasce \& Avendaño, 2020; Federico et al., 2017; Frimer et al., 2014; Manson et al., 2020; Malka et al., 2017; McFarland et al., 1992, 1993, 1996; Pentony et al., 2000; Todosijević, 2005; Todosijević \& Enyedi, 2008; Van Hiel et al., 2006; Wronski et al., 2018).

Indeed, the case for LWA has been bolstered by a recent new wave of research that has sparked a re-emergence of interest in the construct. This renewed interest is evidenced by the well-attended symposium on LWA at the most recent Society for Personality and Social Psychology Conference (Conway, 2020) and by an increase in recent publications and citations relevant to the topic (e.g., Conway et al., 2018; Conway \& McFarland, 2019; Conway et al., 2020; Conway et al., in press; Costello et al., 2020; 
Fasce \& Avendaño, 2020; Federico et al., 2017; Frimer et al., 2014; Manson, 2020; Proch et al., 2018; Vasilopoulos et al., 2018; Wronski et al., 2018).

Yet, in spite of this renewed energy for LWA and the growing body of evidence in favor of its validity as a measured psychological construct, skepticism remains (e.g., Nilsson \& Jost, 2020). Thus, clearly more definitive work is needed. Inspired by criticisms of both the empirical phenomenon and the theoretical construct, in the present paper, we present novel evidence using multiple approaches for validating the utility of LWA. This array of evidence spans multiple independent types of validity, including (1) descriptive evidence from the American populace about their likelihood of knowing highLWA persons, (2) content validity tests of a recently-developed LWA questionnaire revealing that participants explicitly rate the items as measuring authoritarianism, (3) tests showing that this LWA measure is related to substantive domains (perceived threat, restrictive norms, negative outgroup perceptions, dogmatism, and attitude strength) that authoritarianism theory suggests it ought to be related to (above and beyond political ideology), and (4) a world-wide survey demonstrating that some countries exhibit higher levels of left-wing authoritarianism (LWA) than right-wing authoritarianism (RWA). Further, the present set of studies uses two different approaches for separating liberal non-authoritarians from liberal authoritarians: Controlling directly for ideology (thus isolating the authoritarian part of left-wing authoritarianism) and looking only withingroup at liberals (thus comparing liberal non-authoritarians to liberal authoritarians). This array of novel triangulating evidence overwhelmingly suggests that left-wing authoritarianism is a fact rather than a fable. 
Below, we first describe the current basis of skepticism surrounding LWA. We then present reasonable scientific standards of evidence for judging whether the heavilycriticized LWA construct is a realistic and relevant phenomenon after all. Then we proceed to twelve studies demonstrating that LWA is, indeed, realistic and relevant.

\section{The Basis of Skepticism About LWA}

\section{Altemeyer's LWA Evidence}

Historically, much of the skepticism about LWA can be traced to Altemeyer's work on the construct. After constructing an LWA scale purported to be parallel to his RWA scale, he found almost no evidence of LWA, indeed famously reporting that highLWA persons were “as rare as hen's teeth in my samples” (Altemeyer, 1996). This lack of evidence from Altemeyer has often been one of the key arguments cited to suggest that LWA does not exist. For example, in their highly-cited paper on ideology (one of the most influential papers in the history of the topic, having been cited over 4,400 times on Google Scholar), Jost et al (2003)'s dismissal of LWA as a construct prominently featured Altemeyer's research. Indeed, one does not have to read far into Jost et al.'s (2003) classic paper to see how much of their own view of the rigidity of the right is based on Altemeyer's work. For example (Jost et al., 2003; p. 353):

“Altemeyer (1998) concluded, 'I have yet to find a single "socialist/Communist type" who scores highly (in absolute terms) on the [Left-Wing Authoritarianism] Scale. Shils may have been right about his era, but the "authoritarian on the left" has been as scarce as hens' teeth in my samples' Evidence suggests that dogmatism has been no more useful than the construct of authoritarianism for identifying rigidity of the left..." 
This reliance on Altemeyer's evidence by skeptics of LWA would be rather alarming even if the evidence was particularly compelling, because it is based on only a few samples from one cultural context. However, it is especially troubling because upon closer inspection, Altemeyer's evidence is itself deeply flawed even in describing that one cultural context. For example, although his LWA questionnaire was intended by his own stated goal to be parallel to his RWA scale, it is clearly not parallel in multiple largescale ways. Specifically, Altemeyer's LWA scale adds two highly salient item features not present in the RWA scale.

First, Altemeyer's LWA scale requires participants who score high on the questionnaire to support a revolution to overthrow the established government. In fact, twenty of the twenty-two items on Altemeyer's LWA scale reference a revolutionary movement. For example: "The members of the Establishment deserve to be dealt with harshly, without mercy, when they are finally overthrown." By contrast, none of the items on any of Altemeyer's RWA scales makes a single reference to violent upheavals overthrowing the establishment. Second, whereas the RWA and LWA scales both use vigorous authoritarian, negative, dogmatic, and punitive language, only the LWA items leave absolutely no doubt that the endorsement of violence is explicitly required to score high on the scale. For example: "The conservative right-wing Establishment will never give up its power peacefully, so a revolutionary movement is justifying in using violence to crush it."

Thus, Altemeyer's RWA and LWA scales are not parallel in very important ways. Indeed, whereas Altemeyer's RWA scale reads like a measure of general authoritarianism, Altemeyer's LWA scale reads like a screening instrument for joining a 
violent revolutionary group that wants to overthrow the government. As a result, the fact that few people scored high on Altemeyer's LWA scale tells us little about left-wing authoritarianism. Rather, it simply tells us the obvious fact that, whether left-wing or right-wing, few people want to endorse, let alone join, a violent military movement designed to attack and overthrow something else. However, historically, some of academia's dismissal of LWA was based on this clearly flawed evidence from Altemeyer.

These flaws were partially addressed by Conway and colleagues (2018) when they used a version of Altemeyer's RWA scale to create a more parallel LWA scale. These researchers thus bypassed the issue of the revolution/aggression asymmetry by mirroring Altemeyer's RWA scale - which did not contain such language - to create a new LWA scale. Unlike Altemeyer's original LWA scale, this new LWA scale kept much of the same authoritarian language as the original scale - only it replaced conservative authorities with liberal authorities. When this more parallel scale is used to measure LWA, evidence of LWA is manifest, often at effect sizes similar to those for RWA (Conway et al., 2018; Conway \& McFarland, 2019; Conway et al., in press; Fasce \& Avendaño, 2020). Further, Conway et al's LWA scale predicts (1) voting intentions in the 2016 election (Conway \& McFarland, 2019), (2) distrust of opponents, reactance, and support for divisive behaviors (Conway et al., in press), and (3) a reactive stance against reward for application (Fasce \& Avendaño, 2020).

\section{The Double-Barreled Nature of Authoritarianism}

A second basis of skepticism, although arguably historically less important, is more scientifically plausible. That skepticism is based in the fact that Left-Wing 
Authoritarianism is a double-barreled construct. Because it contains both ideological (left-wing) content and authoritarian content, it can be a challenge to disentangle the degree that LWA effects are the result of authoritarianism or the result of ideology. For example, Honeycut and Jussim (2020) recently wondered about Conway et al's (2018) LWA evidence: "Of course, this problem is itself confounded with the measurement problem - is anyone shocked that conservatives score higher than liberals on a rightwing authoritarianism scale, whereas liberals score higher than conservatives, on a leftwing authoritarianism scale?" The implication is clear: Because LWA simultaneously measures both ideology and authoritarianism (that is, because it is both left-wing and authoritarian), how can we be sure that any results we find are truly about authoritarianism per se? Perhaps those findings could be explained without considering authoritarianism at all.

This is a perfectly reasonable measurement concern. However, it is not a problem specific to LWA measurement: It is a problem likely inherent in any authoritarianism measurement. Right-wing authoritarianism also has both ideological content (right-wing) and authoritarianism embedded into the construct. Indeed, no matter what you put in the blank, [blank] authoritarianism will be double-barreled in some sense, because it will have both some content (the "[blank]") and also authoritarianism built in.

Importantly, this is not simply a problem with specific researchers designing specific scales; rather, it is a measurement challenge likely inherent in authoritarianism itself. Authoritarianism is almost certainly expressed primarily in domain-specific ways (Conway et al., 2020), and as a result, all authoritarianism questionnaires must in some sense (either explicitly or implicitly) answer the question "authoritarianism to WHAT?" 
Few people walk around acknowledging every authority figure's legitimacy, and even when specific authority figures are not stated on a questionnaire, they will likely be imagined by respondents (see, e.g., Frimer et al., 2014). Indeed, the way the construct is historically defined unequivocally means that those high in authoritarianism actually draw sharper lines denouncing outgroup authority figures. Persons high in authoritarianism are especially likely to adhere to one authority and group and, as a result, to reject other authorities and groups. Right-wing authoritarians adhere to religious and conservative authorities - but they are especially likely to reject scientific and liberal authorities. In much the same way, we would expect left-wing authoritarians to adhere to a different set of authorities than right-wing authoritarians, and to reject a different set of authority figures as well. For example, left-wing authoritarians would be more likely to adhere to their liberal college professors while rejecting their religious parents.

And yet this state of things does not invalidate that authoritarianism is an important construct with real-world consequences. The fact that a right-wing authoritarian clings to religious authorities but rejects scientific authorities does not make them less authoritarian. Likewise, the fact that a left-wing authoritarian clings to liberal authorities but rejects conservative ones does not make them less authoritarian.

However, in both cases, it does pose a measurement challenge: How are we to separate the ideological parts from the authoritarian parts? In the case of LWA, how do we separate liberal non-authoritarians from liberal authoritarians? This is, in fact, one of the primary challenges critics have levied at LWA research (Nilsson \& Jost, 2020). In the next section, we address this exact question by drawing on established methods in social psychology for this specific measurement challenge. Then, across multiple studies, 
we provide evidence that suggests it is liberal authoritarianism, and not just liberalism, that is involved in our key effects.

\section{Scientific Standards of Evidence for LWA}

When approaching any scientific issue, it is important to apply the same standards of evidence on all sides of a discussion (Tetlock, 1994). In the present case, this issue is pertinent in several important ways.

\section{Equivalent Standards for RWA and LWA}

Altemeyer's RWA scale - on which Conway et al's (2018) LWA scale was based - has historically been, and still is, by far the most extensively-used measurement of the right-wing authoritarianism construct. For example, an empirical study (Conway et al., 2018) showed that $79 \%$ of the scales from recent research that measured RWA used a version based on Altemeyer's scale - either Altemeyer's original RWA scale (62\%) or the short version constructed by Zakrisson (2005; 17\%). Indeed, even since 2018, Altemeyer's RWA scale has continued to be widely-used in top journals (including Journal of Personality and Social Psychology and Personality and Social Psychology Bulletin), and in most cases used in a manner that assumes it is measuring authoritarianism and not just ideology (see Conway et al., 2020).

The scientific consensus thus overwhelmingly favors the conclusion that Altemeyer's scale measures authoritarianism above and beyond ideology. Indeed, it is the past and present scientific standard in the field for measuring authoritarianism, and decades of scientific knowledge about the construct - knowledge often accepted as axiomatic - has been built upon it. And for good reason: As we will see in Study 2, it is an excellent face valid measurement of authoritarianism. Thus in this case the scientific 
consensus is correct: Altemeyer's RWA measurement, though not without flaws, is a good measure of general right-wing authoritarianism.

Given this, it is important that we apply the same standards of evidence to judging LWA that have been used to arrive at that conclusion for RWA. Consider the case of Conway et al.'s (2018) LWA scale used in the present set of studies. Unlike Altemeyer's own LWA scale, Conway et al's LWA scale mirrors the language of the most-validated and widely used RWA scale (Altemeyer's RWA scale that represents the historical and current scientific consensus on the topic). As a result, Conway et al's LWA scale possesses high content validity as a measure of authoritarianism.

Consider that participants who score high on the LWA scale agree that (italicized words are direct quotes from the LWA scale): Our country needs a mighty leader, that the leader should destroy opponents, that people should trust the judgment of the proper authorities, should avoid listening to noisy rabble rousers in our society who are trying to create doubts in people's minds, should put some tough leaders in power who oppose those values and silence the troublemakers, should smash the beliefs of opponents, that what our country really needs is a strong, determined leader who will crush the evil, that society should strongly punish those they disagree with, deny that their opponents have a right to be wherever he or she wants to be, and support the statement that the country would be better off if certain groups would just shut up and accept their group's proper place in society. These items hit all of the hallmarks of the consensus conceptualization of the authoritarian person. For decades, it has been assumed that if people agreed with those statements when the targets of authoritarianism were conservative and the outgroups were liberal, then they were indeed authoritarians. Therefore, if people agree 
with those statements when the targets of authoritarianism are liberal and the outgroups are conservative, we must - applying the same standard - also agree that they are authoritarians. If we grant that someone saying they want to put some tough leaders in power who oppose those values and silence the troublemakers is authoritarian when referring to right-wing leaders, then we also have to grant that someone saying the exact same thing when referring to left-wing leaders is also an authoritarian.

\section{Separating "Liberal" From "Liberal Authoritarian"}

But of course, although important, content validity is just one aspect of validity. While LWA passes the content validity test (something we return to in Study 2 more explicitly), what standards can we use to solve the measurement challenge posed by a double-barreled construct? As we noted earlier, one of the difficulties with measuring authoritarianism is that it is inherently content- and value-based. Because authoritarianism focuses on submission to authorities (see e.g., Duckitt et al., 2010; Feldman, 2003), it is hard to consider the construct without considering what authorities people are submitting to.

In a recent presentation on this psychometric conundrum, Conway (2020) offered several solutions to the double-barreled measurement problem inherent in authoritarianism. All of these solutions are drawn from basic social psychological methods, and many of them have served as the basis for accepting RWA as a measurable construct. As a result, evidence along these lines should apply equally to LWA. We cover these solutions next.

Use ideologically-neutral scales. Because the authoritarianism construct is inherently about commitment to specific authorities and rejection of others, it is very 
difficult, if not impossible, to write an ideologically-neutral authoritarianism scale. However, some language is more ideologically-neutral than others. In Study 12, we use one such scale that has less ideologically-loaded language to demonstrate the existence of LWA around the world.

Use parallel ideologically-loaded scales. In classic research paradigms, researchers attempt to isolate specific variables while holding everything else constant. Thus, one method for isolating authoritarianism is based in basic experimental logic and involves writing equivalent scales for RWA and LWA. To the degree that (1) all words related to authoritarianism for both RWA and LWA are face valid measurements of authoritarianism, (2) all words related to authoritarianism are essentially identical for both RWA and LWA, and (3) the only thing varied across scales is the type of authoritarian submitted to, we can infer that (4) similarities in effects across scales are reasonably attributed to authoritarianism, whereas (5) differences in effects across scales are reasonably attributed to the type of authority figures (or other aspects associated with conservative versus liberal content).

While a useful starting point, this method is dependent on outcome measures that themselves are ideologically neutral. We employ this method in Study 3 on one fairly ideologically-neutral outcome measurement. However, this method is rarely (if ever) enough on its own, and many times one would expect different covariates of scores on the two types of authoritarianism questionnaires for theoretically-expected reasons. As a result, we view it important to use this method in tandem with the other methods described below. 
Use ideologically-loaded scales that control for ideology. The most typical way to isolate the effect of one variable over and above another variable is to control for the second variable (Hayes, 2013; Preacher, 2015; Darlington \& Hayes; 2017 Hayes \& Rockwood, 2020). This has a straightforward application to both RWA and LWA: If scientists want to isolate the "authoritarian" part of " $\mathrm{X}$ " Authoritarian, they can statistically control for "X." Thus, if we aim to isolate the "authoritarian" part of leftwing authoritarianism, we can control for participants' ideology (“left-wing/right-wing”). While this method is not perfect, if effects of LWA remain after controlling for ideology, it nonetheless suggests that something beyond liberal ideology is accounting for those effects. As we will see across Studies 3-11, we believe that the something beyond is best categorized as authoritarianism.

Use ideologically-loaded scales within the focal group. A complementary method for separating out ideology from authoritarianism is to perform withinideological group analyses (see Wronski et al., 2018, for an example). This method has the disadvantage of truncating the range and discarding available data. But on the other hand, it gains a simple heuristic advantage: If one, for example, finds an effect of RWA only within conservative persons, then it suggests that the effect is not driven by ideology (since that is held roughly constant in within-ideological group analyses), but by authoritarianism. Similarly, if one finds an LWA effect only within liberal persons, then this suggests the effect of LWA is driven by authoritarianism and not left-wing ideology. In other words, one way to separate liberal authoritarians from liberal non-authoritarians is to look only at liberals. 
To accomplish this, in Study 11 we performed further analyses that analyzed all key LWA effects by looking within liberal groups. As we will see, both across-group and within-group analyses overwhelmingly support the idea that there is something beyond mere ideology at play here; that something beyond is, we believe, best described as authoritarianism.

\section{The Present Studies}

Informed by this set of standards, we below present a wide array of novel evidence concerning the real-life prevalence and importance of LWA within (Studies 111) and outside (Study 12) the USA. In Study 1, we ask participants about their own perceptions of LWA persons in their lives (and discover that participants on both sides of the political spectrum, to a surprising amount, identify a descriptively important number of left-wing authoritarians in their own lives). In Study 2, we ask participants to judge the degree that items from Conway et al's (2018) LWA questionnaire are measurements of authoritarianism (and discover that they are rated as good measurements of authoritarianism). In Studies 3-10, we evaluate the degree that persons scoring high on this LWA scale show the properties that prominent authoritarianism theories suggest an authoritarian person should have. Studies 3-6 reveal that persons high in LWA show heightened sensitivity to threat. Study 7 shows high-LWA persons have more support for a restrictive social norm. Studies 8 and 9 reveal that high-LWA participants show more negative ratings of African-Americans and Jews, while Study 10 reveals that high-LWA participants show more domain-specific dogmatism and attitude strength. Across all studies 3-10, these effects remain when controlling for political ideology. Further, Study 11 reveals that the majority of the effects hold when looking only within liberals, thus 
revealing these effects are about liberal authoritarianism and not just liberalism in general. Study 12 uses the World Values Survey to provide evidence of Left-Wing Authoritarianism around the globe.

\section{Study 1}

\section{Methods}

The focus of Study 1 was purely descriptive in that it evaluated the everyday occurrence of authoritarianism in lay populations. For Study 1, we gave participants categories of persons (e.g., family, co-worker) and asked them to identify authoritarians in their lives on both sides of the political spectrum.

Participants. Four hundred forty-one U.S. adults were recruited using Amazon's Mechanical Turk (MTurk). MTurk has been validated for use as a representative sample for research related to politics and political ideology (see, e.g., Clifford, Jewell, \& Waggoner, 2015, Kennedy et al., 2018) and generally shows similar results as other samples (e.g., Houck et al., 2014). Further, MTurk has been validated for use in work on authoritarianism (Choma \& Hanoch, 2017; Ludeke et al., 2018). As a result, MTurk is an excellent choice for work on U.S. authoritarianism. The sample was 55\% female, had an average age of 38, and was slightly left-leaning politically (4.3 on a political conservatism scale with 4.5 as the midpoint).

Initial Directions to Participants. Participants were randomly assigned to one of two different sets of directions. In the first set of directions (Definition Given), we gave participants a standard definition of authoritarianism. This definition was drawn from prior work suggesting that authoritarianism has three primary aspects (e.g., Altemeyer, 1996; Feldman, 2001; Duckitt et al., 2010): 
In this study, we are interested in your views of authoritarianism and authoritarian people. First, we will describe what we mean by authoritarianism. Authoritarianism involves a need for group cohesion and the subordination of individual autonomy to the group and its authority. Authoritarian persons can potentially be a part of any group - to be considered authoritarian, it does not matter to what group they belong. Rather, regardless of the type of group, authoritarian persons generally have the following characteristics: Authoritarian persons have attitudes favoring obedience to group leaders and authorities. Authoritarian persons have attitudes favoring harsh, coercive social control (e.g., punishment, aggression). Authoritarian persons have attitudes favoring conformity to established group norms and values.

Participants in the other condition (Definition Generated) were given no definition, but instead were asked to generate their own definition:

In this study, we are interested in your views of authoritarianism and authoritarian people. First, we would like to get your own thoughts on what you think an authoritarian person is. So in the space below, please type a description of what you think someone who is authoritarian would be like.

Participants in this condition generally seemed to understand the authoritarianism construct and, as we will see below, our key interpretations were unaffected by the directions manipulation.

Authoritarianism Measurements: Mean Number. Participants then completed a series of parallel measurements asking them how many authoritarians they could identify in their lives across various categories for both liberals and conservatives. For example, participants were asked: In your family (including all extended family), how many 
authoritarians can you think of that are politically liberal? They were then given options $0,1,2,3,4,5,6-10$, and more than 10 .

A parallel question was asked for how many family members were authoritarians who were politically conservative: In your family (including all extended family), how many authoritarians can you think of that are politically conservative?

Using this method, we asked participants to identify left- and right-wing authoritarians across four different categories: Family, Friends or Acquaintances, CoWorkers, and News/TV/Movie/Sports Personalities. We further asked participants to simultaneously consider (and report the overall number of) all the authoritarian people they could identify who were politically liberal and politically conservative (scale options $=0,1,2,3,4,5,6-10,11-15$, and greater than 15). To convert these to a single number per variable, when participants chose ranges, we entered the midpoint of the range (e.g., 6-10 became 8 ). When the "greater than" option was chosen, we added two to the end of the range to estimate the number.

We used two primary summary scores with complementary strengths and weaknesses. First, we used participants' own report of the total number of authoritarians they knew on the right and the left (referred to in the tables as TOTAL: REPORTED). We further took the sum of all the four categories (referred to as TOTAL: SUM).

Authoritarianism Measurements: Most Authoritarian Person. Participants were then asked to consider the most authoritarian person they could identify in their life across each of the four categories. In each case, they were asked whether or not the representative most authoritarian person was liberal, conservative, or neither/do not know. Finally, participants were asked to think of the most authoritarian person overall in 
their lives and identify whether the person was liberal, conservative, or neither/do not know. We created an additional summary score conceptually identical to the summary for the mean number measurements by taking the average percentage across the four types of authoritarians.

Participant Ideology. All participants further completed a standard two-item political conservatism scale, with items anchored by liberal/conservative and democratic/republican (e.g., Conway et al., 2012; Jost et al., 2008; Jost et al., 2003). In order to provide easy descriptive summaries, for Study 1 we converted this measurement to a dichotomous measure in a manner identical to prior research (Conway et al., 2016; Conway et al., 2018) by considering people above the mid-point conservative and people below the midpoint liberal (people right at the mid-point were dropped for all analyses including this variable; $n=395$ for those analyses, with 244 liberals and 151 conservatives).

\section{Results and Discussion}

Although the primary purpose of Study 1 is to investigate the descriptive nature of participant perceptions of left-wing authoritarians, we present inferential comparisons for completeness. Descriptive results for all measures are presented in Tables 1 and 2. Because (as the tables reveal) the results tell the same story across all categories, for the sake of brevity, in this narrative we focus only on the overall summary scores.

We first tested the influence of our directions manipulation by running 2 (Definition Instructions: Definition Given versus Definition Generated) X 2 (Type of Authoritarian Considered: Liberal versus Conservative) Mixed-Model ANOVAs, with Instructions as the Between Subjects variable and Type of Authoritarianism as the 
Within-Subjects variable. Participants reported more authoritarians in the Definition Given condition than in the Definition Generated condition, $F$ 's $>8.7, p$ 's $<.004$.

However, this did not significantly differ by type of authoritarianism, interaction $F$ 's < $.90, p$ 's $>.34$. Similarly, there was no significant interaction between the instructions manipulation and the type of authoritarianism on the two summary most authoritarian person measurements, $p$ 's $>.15$. As a result, we subsequently dropped the instructions manipulation for ease of understanding; however, including it would not substantively change any of the conclusions drawn from Study 1 below.

\section{$\underline{\text { Table I }}$}

Study 1: Identification of Left- and Right-Wing Authoritarians in Everyday Life

\section{Liberal Conservative Authoritarians Authoritarians}

$\begin{array}{lrr}\text { Mean Number of Authoritarians } & & \\ \text { Family } & 1.7 & 2.8 \\ \text { Friends } & 2.4 & 2.8 \\ \text { Co-Workers } & 2.4 & 2.8 \\ \text { News/TV/Movie/Sports } & 5.1 & 6.0 \\ \text { TOTAL (SUM) } & \mathbf{1 1 . 7} & \mathbf{1 4 . 4} \\ \text { TOTAL (REPORTED) } & \mathbf{7 . 8} & \mathbf{1 0 . 3} \\ & & \\ \text { Most Authoritarian Person } & & 57 \% \\ \text { Family } & 33 \% & 48 \% \\ \text { Friends } & 36 \% & 51 \% \\ \text { Co-Workers } & 27 \% & 50 \% \\ \text { News/TV/Movie/Sports } & 38 \% & \mathbf{5 2 \%} \\ \text { TOTAL (AVERAGE) } & \mathbf{3 3 \%} & \mathbf{6 1 \%} \\ \text { TOTAL (REPORTED) } & \mathbf{3 4 \%} & \end{array}$

Notes: $N=441$. 
Consistent with prior assertions that right-wing authoritarianism is more prevalent than left-wing authoritarianism, participants reported significantly more right-wing authoritarianism for all summary measures of both mean number and most authoritarian person measures, all within-subjects $F^{\prime}$ s $>19.0, p$ 's $<.001$. However, more important to our present purpose, participants consistently identified a large number of left-wing authoritarians as well. As seen in Table 1, participants self-reported identifying 7.8 liberal authoritarians on average, and the sum total of the identified liberal authoritarians across the four categories was 11.7 authoritarians. ${ }^{1}$

As Table 2 indicates, this remains the case even when focusing only our liberal participants. $^{2}$ As seen in Table 2, liberal participants self-reported identifying 6.6 liberal authoritarians on average, and the sum total of the identified liberal authoritarians (identified by liberal participants) across the four categories was 10.5 authoritarians. $^{3}$

\footnotetext{
${ }^{1}$ We can only speculate as to the reason for the discrepancy between these two measures. Possible explanations include (1) the same authoritarian could appear across multiple categories (e.g., one authoritarian might be a co-worker and a friend), or (2) participants might be biased in their reporting of the overall score, such that it tends to underestimate the actual number when all authoritarians are added together. We cannot determine from our data which of these two is the correct explanation, although the nearly-identical correspondence of the parallel measures for the most authoritarian category suggest that participants' scores more generally line up in this regard (and thus perhaps might suggest the first, and not the second, explanation). However, the larger point remains - regardless of the measure used, participants reported a substantial amount of left-wing authoritarianism.

${ }^{2}$ A set of 2 (Participant Ideology: Definition Given versus Definition Generated) X 2 (Type of Authoritarian Considered: Liberal versus Conservative) Mixed-Model ANOVAs (with Participant Ideology as the Between Subjects variable and Type of Authoritarianism as the Within-Subjects variable) revealed an interaction between ideology and authoritarianism type on mean number of authoritarians and most authoritarian person summary scores, $F^{\prime}$ 's $>6.5, p$ 's $<$ .02. Consistent with an Authoritarian Norm Fit Model that posits liberals in the U.S. are more motivated than conservatives to avoid authoritarian ingroup labels (Conway, McFarland, Costello, \& Edelman, 2020; Conway, Zubrod, \& Chan, 2020), the pattern predictably suggests that, in the main, liberals are more likely (versus conservatives) to identify authoritarians in outgroups than ingroups. However, this is orthogonal to the main point of Study 1 .

${ }^{3}$ We also did analyses using a more stringent criterion for considering someone a liberal. Participants answered two categorical ideology questions as well in Study 1, and for this supplementary analyses, we considered someone a liberal if they self-identified as both a "liberal" and a "democrat." While this predictably yielded fewer liberals overall than those reported in the text, the substantive results reported in the main text are essentially identical in their import to these supplementary analyses. No matter how they are sliced, the present data reveal a consistent story: Participants of all political persuasions reported a lot of evidence of left-wing authoritarianism.
} 
$\underline{\text { Table II }}$

Study 1: Identification of Left- and Right-Wing Authoritarians in Everyday Life, By Political Identification of the Participant

Liberal Participants Conservative Participants

\begin{tabular}{llll}
\hline Liberal & Cons. & Liberal & Cons.
\end{tabular}

$\begin{array}{lrrrr}\text { Mean Number of Authoritarians } & & & & \\ \text { Family } & 1.6 & 2.6 & 1.8 & 3.1 \\ \text { Friends } & 2.5 & 2.6 & 2.4 & 3.2 \\ \text { Co-Workers } & 2.3 & 2.9 & 2.5 & 2.9 \\ \text { News/TV/Movie/Sports } & 4.0 & 6.6 & 6.7 & 4.9 \\ \text { TOTAL (SUM) } & \mathbf{1 0 . 5} & \mathbf{1 4 . 8} & \mathbf{1 3 . 4} & \mathbf{1 4 . 0} \\ \text { TOTAL (REPORTED) } & \mathbf{6 . 6} & \mathbf{9 . 0} & \mathbf{1 1 . 3} & \mathbf{8 . 5} \\ & & & & \\ \text { Most Authoritarian Person } & & & & \\ \text { Family } & 34 \% & 57 \% & 31 \% & 60 \% \\ \text { Friends } & 34 \% & 52 \% & 37 \% & 53 \% \\ \text { Co-Workers } & 23 \% & 57 \% & 34 \% & 41 \% \\ \text { News/TV/Movie/Sports } & 29 \% & 60 \% & 50 \% & 37 \% \\ \text { TOTAL (AVERAGE) } & \mathbf{3 0 \%} & \mathbf{5 6 \%} & \mathbf{3 8 \%} & \mathbf{4 8 \%} \\ \text { TOTAL (REPORTED) } & \mathbf{2 4 \%} & \mathbf{7 1 \%} & \mathbf{4 9 \%} & \mathbf{4 8 \%}\end{array}$

Notes: Total $N=395$. Conservative participant $n=151$; liberal participant $n=244$.

Indeed, all the mean numbers for liberal authoritarians (both individual categories and summary scores) presented in Tables 1 and 2 are significantly different from zero using one-sample $t$-tests ( $p$ 's <.001). More importantly, the descriptive statistics reveal that most people report identifying a substantial number of left-wing authoritarians in their lives. Further, even liberal participants report that $24 \%$ (or 30\%, depending on the summary measure) of their most authoritarian persons are, in fact, liberal. In the present 
study alone, that would translate to (at a minimum) 58 extremely left-wing authoritarians identified by liberal participants. As a thought experiment, extrapolated to the U.S. population as a whole, these data would mean that tens of millions of people - including liberals - would identify a left-wing authoritarian as the most authoritarian person in their life. This would translate to literally millions of (very real) left-wing authoritarians in the U.S. presently, across all walks of life. This thought experiment would hold true even if one excludes the TV personality category that would likely include quite a bit of overlap across persons, and instead focus on categories where across-person overlap would be minimized. Thus, while the present data do suggest participants identify more right-wing than left-wing authoritarians, they also suggest that participants - even liberal participants - identify a meaningfully large number of left-wing participants in their lives.

Of course, we do not wish to overstate the importance of these data. We recognize that MTurk, while a valid research resource, does not represent the whole population of the U.S. Further, participants can sometimes be wrong in their interpretations of other people in their lives. Rather, these data suggest that perhaps the debate about left-wing authoritarianism, so ardently discussed in academic circles, is less in evidence in lay populations. The average citizen may feel more confident that left-wing authoritarians exist - as they report knowing many of them.

\section{Study 2}

\section{Overview}

Construct validity is a complicated and multi-faceted concept. At a most basic level, however, construct validity is a simple question: Does a questionnaire set measure what is purports to measure? One of the most basic, direct, and important ways to 
determine if a scale measures what it is supposed to measure is to provide content judgments concerning whether or not scale items are measuring the key construct. Indeed, this method has been used in other authoritarianism work (e.g., Funke, 2005; Dunwoody \& Funke, 2016). In Study 2, we thus provided such direct validity evidence by asking participants if items from commonly-used LWA and RWA questionnaires do, in fact, measure authoritarianism. To the degree that participants believe they do, this provides a piece of evidence (in a larger puzzle) that LWA is a real construct that is meaningfully measured by a recently-developed LWA scale.

\section{Methods}

Because Conway et al's (2018) LWA scale was purposefully designed to be parallel to a version of Altemeyer's (1996) RWA scale, we selected parallel items from each scale for this validity test. For a discriminant validity comparison group, we further selected items from a widely-cited Big 5 Personality inventory. In all cases, we asked participants to identify the degree that they believed that someone scoring high on an item would be an authoritarian person.

Participants. Four hundred seventeen U.S. adults ( $50 \%$ female, mean age $=38)$ were recruited using Amazon's Mechanical Turk (MTurk). The sample was slightly leftleaning politically (4.2 on a political conservatism scale with 4.5 as the midpoint). Participants were randomly assigned to receive one of the three sets of parallel items described in more detail below: RWA, LWA, or De-Politicized LWA.

Instructions to Participants. All participants were first given the definition of authoritarianism used in Study 1's Definition Given condition, which contains a summary of the widely-accepted three-aspect model of authoritarianism. Then participants read a 
description of their task:

Now we are going to present you with questions which may or may not measure authoritarianism. Your task is NOT to answer questions about your own agreement with the question. Rather, your task is simple: It is to judge whether or not the question presented is a legitimate measurement of an authoritarian person. Specifically, for each of the following questions, while considering the definition of authoritarianism (and each of the three characteristics mentioned above), we would like for you to state whether you think someone who answered "yes" to the question would be an authoritarian person, using the following scale: 1 = I cannot tell from someone's answer to this item whether that person is authoritarian or not. 2 = Someone who answered "yes" might be authoritarian, but it is not very clear. $3=$ Someone who answered "yes" to this item is very likely authoritarian.

After that, participants were presented items (described below) for making judgments. Prior to each item, they were reminded of the nature of their task ("Imagining what it would mean if OTHER PEOPLE responded 'yes,' consider the following item:"). Selection of LWA and RWA items. From the LWA and RWA scales, we selected all the pro-trait items (see Appendix for all items) for this validity test. (Note that because the scales use parallel wording, this means that each scale had the same set of "base" items). This decision was based on the nature of the task: We deemed that trying to ask participants to "reverse" the item to see if someone who scored low would be high in the authoritarianism trait might in this instance be an unnecessarily difficult task - and that this fact would subsequently make interpretation difficult. As a result, throughout we 
focused only on pro-trait items from all scales. This left 10 items each to be used in the validity test for both LWA and RWA.

For LWA, we further created a set of De-Politicized LWA items by removing all clearly political language (such as "liberal" and "conservative") and, when necessary, replacing politicized words with generic alternatives (e.g., replacing "progressive ways and liberal values" with "our group's values"). The goal of these items is to see what, if any, biases people might have in making attributions about authoritarianism to leftversus right-wing persons. To the degree that the de-politicized items are rated by participants as more authoritarian, it suggests the items are measuring authoritarianism but people are biased to believe otherwise (as some research suggests they will be; Frimer et al., 2014).

Selection of Big 5 Inventory Items. For discriminant validity, we further selected the 9 pro-trait items from the highly-cited MINI Big 5 Inventory (Donnellan et al., 2006; see Appendix).

Task description. Participants were always presented with 19 (10 RWA/LWA + 9 Big 5) items in a random order and asked to make a judgment about each item. Participants in both RWA and LWA conditions always had the same discriminant validity comparison Big 5 items. Regardless of item type, for each item, participants judged on a 1-3 scale whether or not someone who responded "yes" to that item would, in fact, be an authoritarian.

Participant Ideology. All participants further completed the same standard twoitem political conservatism scale used in Study 1. As in Study 1, in order to provide easy descriptive summaries, for Study 2 we converted this measurement to a dichotomous 
measure in a manner identical to prior research ( $n=365$ for those analyses, with 236 liberals and 129 conservatives).

\section{Results and Discussion}

As seen in Figure 1, results revealed clear evidence of discriminant validity for both LWA (standard and de-politicized) and RWA as an authoritarianism measurement. Paired-sampled $t$-tests comparing each authoritarianism questionnaire set's average to the average from the comparison group revealed strong and significant validity effects for LWA $(t[135]=19.13, p<.001)$, De-Politicized LWA $(t[140]=20.28, p<.001)$, and RWA $(t[135]=22.12, p<.001)$. Looked at another way, one-sample t-tests revealed that all six tests significantly differed from the mid-point of the scale (2), with the authoritarianism questionnaires skewing greater than the midpoint $\left(t^{\prime}\right.$ 's $>12.1, p$ 's $\left.<.001\right)$ and the Big 5 questions skewing below the midpoint $(t$ 's $<-.14 .6, p$ 's $<.001)$. This suggests that the authoritarianism questions for all three scales are indeed measuring authoritarianism - as they lean heavily towards the "very likely authoritarian" end of the scale - while the Big 5 questions do not measure this construct.

These metrics overwhelmingly provide content validity support for the pro-trait items in Conway et al's (2018) LWA measurement. As can be seen from Figure 1, however, LWA did show slightly lower (though still high in absolute terms) discriminant validity than RWA. And indeed, a 2 (within subjects discriminant validity: authoritarianism versus Big 5) X 3 (between subjects authoritarianism scale type: LWA versus RWA versus De-Politicized LWA) mixed-model ANOVA revealed an interaction between Authoritarianism/Big 5 and Type of Authoritarianism scale. To better understand the nature of this interaction, we performed two additional, and more focused, 
2X2 interactions: Whereas the scale type by discriminant validity interaction was significant when comparing LWA and RWA (scale type by discriminant validity interaction $F=6.84, p=.009$ ), this same interaction was not significant for comparing De-Politicized LWA to RWA ( $F<0.69$, interaction $p=.406)$. These additional analyses suggest that part of the reason why the LWA scale was lower in validity was a (small but real) general bias against believing liberals could be authoritarian (see Frimer et al., 2014). When language was removed from the LWA scale indicating to participants a liberal leaning of the scale, the LWA scale showed very similar discriminant validity to the RWA scale (see Figure 1).

Regardless of these small differences across scale types, the present results clearly provide direct evidence of the content validity of the LWA scale as a measurement of authoritarianism. It showed strong discriminant validity. Not only did participants rate it as substantially higher than a scale not designed to measure authoritarianism, but they also rated it as significantly leaning towards the end of the scale clearly indicating it is measuring authoritarianism in absolute terms. 


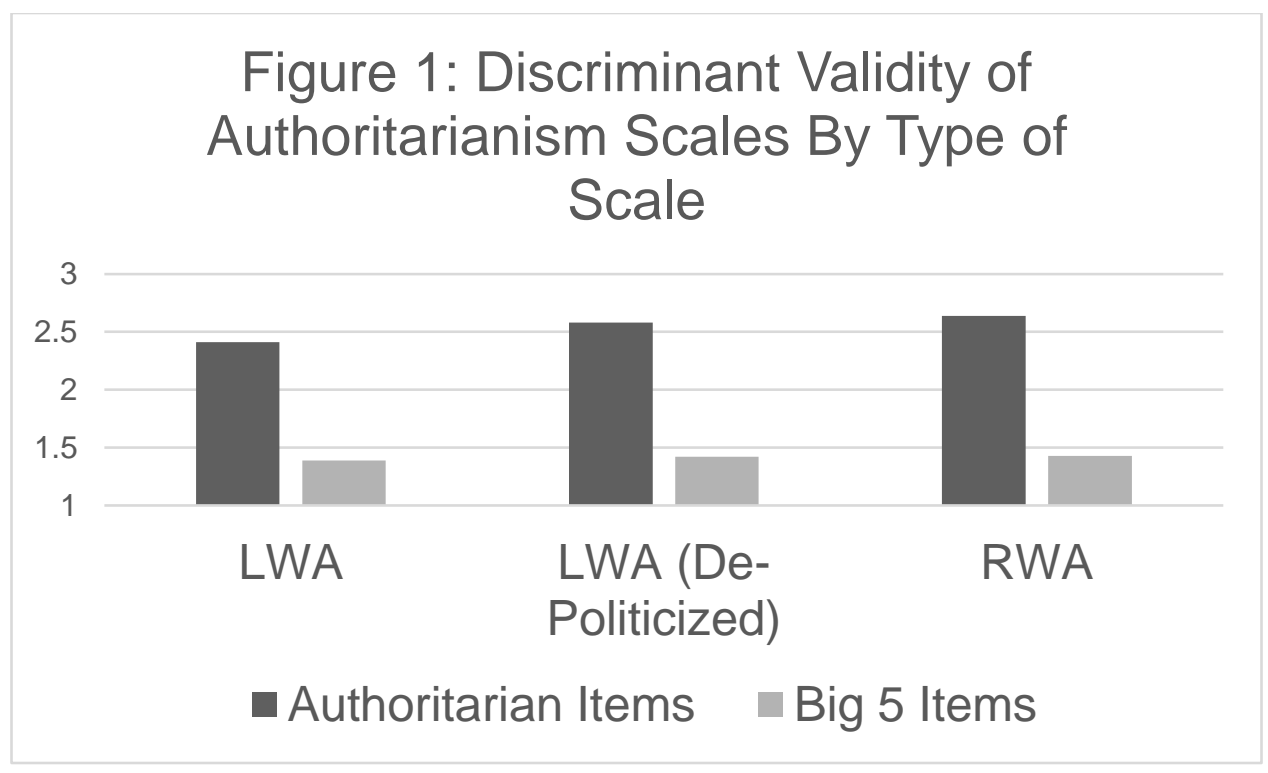

Transition to Studies 3-6: The Importance of Threat Perceptions to Authoritarianism Theories

Almost all prominent theories of authoritarianism maintain that it is psychologically linked to perceptions of threat or danger (e.g., Altemeyer, 1998; Duckitt et al., 2010; Feldman, 2003; Jost et al., 2003; Peterson \& Gerstein, 2005; see Choma \& Hanoch, 2017, for discussion). Indeed, it is "widely accepted" that authoritarianism and threat are empirically linked (Duckitt, 2013, p. 1).

However, essentially all of the work on the threat-authoritarianism relationship has focused on authoritarianism for conservatives (e.g., Altemeyer, 1998; Choma \& Hanoch, 2017; Choma \& Hodson, 2017; Jost et al., 2003; Ludeke et al., 2018; for discussions and evidence of the prevalence of RWA, see Chan et al., 2018; Conway et al., 2018; Malka et al., 2017). We would expect, if LWA is measuring authoritarianism, to find evidence that LWA is also related to measurements of threat perceptions.

Because ideology often overlaps with various outcome measurements, it can be difficult to disentangle the effects of ideology from the effects of other phenomena such 
as threat (e.g., Conway et al., 2018; Duckitt et al., 2010; Thomas, 2013). This problem exists equally for measurements of both RWA and LWA. Conceptually, there are two different ways to solve this methodological problem (see Conway et al., 2018). The first method is to produce ideologically-neutral threat measurements that contain little or no ideological content, and the second is to produce ideologically-balanced threat measurements that include parallel content on both sides. Because these approaches have complementary strengths and weaknesses, in the present package we employ both approaches. Study 4 uses measurements of threat that do not contain any direct ideological content (e.g., perceptions of the amount of ecological threat in the place they live). Some of our studies, on the other hand, use measurements of threat that contain direct ideological content, but either balance that content on both sides (Study 5), or have participants complete parallel measurements of authoritarianism for comparison (Study 6). All studies (3-6) further control for self-reported ideology. As seen below, this triangulating approach provides evidence, across many different ways of conceptualizing threat, that LWA is positively related to threat perceptions - above and beyond political ideology.

\section{Study 3}

\section{Methods}

Study 3 was pre-registered on the Open Science Framework and can be accessed at https://osf.io/gbtdk/?view_only=b3b504d2d98b4c81a1f8d02504409a2c. All predictions were a priori.

Study 3 builds on previous research suggesting that ecological stressors can increase the likelihood of authoritarian societies (Conway et al., 2017). Although that 
research does suggest a link between ecological stress and authoritarianism, it (a) did not have a direct measurement of authoritarianism, (b) did not attempt to produce ideologically-neutral measurements of ecological stress, and (c) did not attempt to address left-wing authoritarianism. Indeed, although the present study uses the individual as the unit of analysis, it is the first study to our knowledge to associate ecological stress perceptions with authoritarianism on the left.

Study 3 was part of a larger study on rigid thinking and health. Several measurements from that study were relevant to our current investigation: Participants from all regions of the United States completed either an RWA or LWA scale, measurements of ecological stress tied to the area in which they lived, a two-item political ideology measure, and a personal income measurement. We expected small effect sizes for both RWA and LWA, and thus we employed a large sample size.

\section{Participants}

A sample of 4,988 U.S. adults were recruited using Amazon's Mechanical Turk (MTurk). The sample was $57 \%$ female and was slightly left-leaning politically (4.2 on a political conservatism scale with 4.5 as the midpoint). One-hundred thirty three participants failed an attention check question, leaving 4,855 for analysis.

Importantly for the present analysis, participants resided in all regions of the United States, including participants from all 50 states. No one region dominated, and percentages from each state reflected the population distribution from the nation as a whole: The largest percentages of participants (by state) resided in California (11\%) Florida (9\%), Texas (8\%), New York (6\%), Pennsylvania (5\%), Ohio (4\%), North Carolina (4\%), Michigan (4\%), Illinois (4\%), and Georgia (4\%). 


\section{Measures}

$\boldsymbol{L W A} / \boldsymbol{R} \boldsymbol{W A}$. Participants were randomly assigned to receive either the 20-item LWA scale (Conway et al., 2018) or the parallel 20-item RWA scale (Altemeyer, 1996).

Ecological Stress Measurements. Participants were asked a series of questions related to the likelihood of prevalence of various ecological threats in the area in which they live. These threats were drawn from prior work on the effect of ecological stress on the emergence of cultural beliefs related to authoritarianism and freedom (e.g., Beall et al., 2016; Conway et al., 2014; Conway et al., 2017; Fincher \& Thornhill, 2012; Kitayama et al., 2006, 2010; Murray \& Schaller, 2010; Oishi et al., 2017; Van de Vliert, 2013; Van de Vliert \& Conway, 2019). These included a question each for pathogen prevalence, natural disaster prevalence, harsh climate prevalence, and mountain (i.e., frontier topography) prevalence. Specifically, items (all anchored on a 1-7 scale) were:

I feel the primary area where I live has a lot of disease.

Ifeel the primary area where I live has a lot of natural disasters.

I feel the primary area where I live has a harsh climate.

Ifeel the primary area where I live has a lot of mountains.

Finally, we included one item that specifically identified stress resulting from dangers in the natural environment (also on a 1-7 scale):

I sometimes feel stressed about the dangers present in the natural environment where I live (including disease, harsh climate, natural disasters, and other forms of environmental stress).

These five items were all modestly correlated with each other and thus we further produced a summary Ecological Stress score (conceptually similar to Conway et al., 
2017) by converting each item to a $z$-score and averaging (standardized $a l p h a=.72) .{ }^{4}$

Co-Variates: Political Ideology and Income. All participants further completed

the same standard two-item political conservatism scale used in Studies 1 and 2.

Replicating past work (Conway et al., 2018), RWA was positively correlated with

political conservatism $(r=.68, p<.001)$, while LWA was positively correlated with

political liberalism (reverse-scored conservatism scale; $r=.58, p<.001$ ). Further,

participants also completed a standard measurement of personal income.

\section{Analytic Strategy}

For Study 3, we performed both zero-order and hierarchical regressions for each ecological stressor predicting LWA and RWA. Hierarchical regressions included political ideology and income at Block 1 , and then each ecological stress measurement (separately) at Block 2. Thus, inferential tests reported for hierarchical regressions at Block 2 are for the added predictive ability of each ecological stressor, beyond ideology and income. ${ }^{5}$

\section{Results and Discussion}

Table 3 presents results from Study 3. As can be seen there, zero-order betas generally revealed that ecological stress measurements predicted both LWA and RWA.

\footnotetext{
${ }^{4}$ Some research suggests that conservatives care more about physical threat - and especially disease/disgust based threat (e.g., Terrizzi et al., 2013) - than liberals do (see Crawford, 2017, for a review). Thus, there is reason to suspect that such threats are not ideologically neutral. And indeed, in a preliminary study $(n=467)$ showing results identical to the pre-registered Study 3 presented here, we found that these ecological threats lean slightly towards conservatives. That was also true in the present study. However, this would actually work against LWA showing a relationship with threat in the present study - and part of the reason why we controlled for ideology directly.

${ }^{5}$ We did not perform analyses with all ecological stressors simultaneously entered at Block 2 because that was not relevant to our current theoretical purpose - and indeed would possibly interfere with it. Entering all ecological stressors at Block 2 would be relevant to questions concerning the unique predictive ability of each ecological stressor above and beyond the other ecological stressors. However, that is beyond our present purpose, which was to test the overall relationship of ecological stress with LWA and RWA. Entering all ecological stressors at Block 2 would in fact unnecessarily remove variance that was important to our purpose (see, e.g., Breiman \& Freedman, 1983, on the dangers of including too many predictors). Thus, all analyses on individual ecological stressors did not include the other stressors.
} 
The overall Ecological Stress summary measurement revealed significant ( $p$ 's $<.001$ ) effects of ecological stress as a predictor, with almost equal effect sizes for LWA and RWA. Looking at the ecological stress measurements separately told a similar story: In all cases except for mountain prevalence predicting LWA, each ecological stress measure significantly predicted both LWA and RWA.

Importantly, subsequent hierarchical regressions entering the summary Ecological Stress measurement at Block 2 revealed Ecological Stress still significantly predicted both LWA and RWA when first entering political conservatism and income at Block 1 (see right half of Table 3), and analyses of individual ecological stress measurements revealed a similar story. ${ }^{6}$

Study 3 revealed clear threat-based predictors of authoritarianism on the right and on the left: Perceptions that ecological stressors were prevalent in their geographic locale - as well as a subjective measurement of danger from those stressors - were significantly positively predictive of both RWA and LWA.

\footnotetext{
${ }^{6}$ Study 3 also included multiple measures related to physical health or health-related activities. These additional measures are not relevant to the present purpose.
} 
$\underline{\text { Table III }}$

Study 3: Individual-level Judgements of Ecological Stress Predicting Left- and RightWing Authoritarianism

Block 2 (Block $1=$ Income and

Zero-Order Conservatism)

$\begin{array}{llll}\text { LWA } & \text { RWA } & \text { LWA } & \text { RWA }\end{array}$

\section{Ecological Stress Measure}

Pathogen Prevalence

Natural Disaster Prevalence

Harsh Climate Prevalence

Mountain Topography Prevalence

Subjective Ecological Stress

TOTAL ECOLOGICAL STRESS

$\begin{array}{llll}.09 * * * & .14 * * * & .12 * * * & .10 * * * \\ .05 * & .12 * * * & .10 * * * & .05^{* * *} \\ .09 * * * & .06 * * & .10 * * * & .03^{\wedge} \\ .03^{\wedge} & .05 * & .07 * * * & .00 \\ .16 * * * & .08 * * * & .13 * * * & .08 * * * \\ .12 * * * & .13 * * * & .15 * * * & .09 * * *\end{array}$

Notes: Total $N=4855$. LWA $N=2470 ;$ RWA $N=2385$. All metrics $=$ standardized betas. Total ecological stress $=$ summary measure $\left(\right.$ see text). ${ }^{*} p<<=.001 ; * * p<=.01 ; * p$ $<=.05, \wedge p<=.10$.

\section{Study 4}

\section{Method}

Participants. As a part of a larger project within the USA on COVID

perceptions, Amazon's Mechanical Turk (MTurk) participants completed nearly-identical batteries of items in Study 4a $(N=297)$, Study 4b $(N=285)$, and Study 4c $(N=502)$

from March 30 to April 3 (2020). ${ }^{7}$ Participants were randomly assigned to complete

\footnotetext{
${ }^{7}$ Given recently-identified potential quality issues with MTurk (e.g., Kennedy et al., 2018), we ensured the highest quality of data by including several screener questions that participants had to answer correctly to be included in the study. Evidence suggests that MTurk still produces excellent data given such safeguards (Kennedy et al., 2018).
} 
either the LWA or RWA measurements from Study $3 .{ }^{8}$ Further, all participants completed measurements related to their perceptions of COVID-19: Perceived threat of COVID-19 and their reaction to government responses. Because the three samples were nearly identical and showed the same pattern, for the sake of brevity we combine them in a pooled analysis.

Coronavirus Threat and Government Response Questionnaires. Participants in Study 4 completed six items concerning how threatened or worried they were about COVID-19, for example: “Thinking about the coronavirus (COVID-19) makes me feel threatened" (standardized alpha $=.88)$.

Participants in Study 4 also completed multiple items concerning their political beliefs about their government's response to the crisis. We focus here on two crossgovernmental dimensions most relevant to participants' feelings of threat related to COVID-19 (all scale alphas > .86): The degree they wanted the government to restrict citizens to help stop the spread of the virus (Restriction; for example, "I support [Federal/State/City] government measures to restrict the movement of American citizens to curb the spread of Coronavirus (COVID-19)"), and the degree that participants wanted their governments to punish citizens who violated social distancing rules (Punishment; for example, "I want my [Federal/State/City] government to severely punish those who violate orders to stay home"). For each belief dimension, participants completed six questions (two for each level of government), and we aggregated the six items for each dimension to create scores for Restriction and Punishment.

\footnotetext{
${ }^{8}$ All three studies contained a paragraph-writing prime at the beginning of the study: Participants wrote about COVID19, a happy topic, a neutral topic, or no topic. However, all the relationships reported here were essentially identical in each priming condition. Further, we found no consistent main effects of the prime on anxiety, self-reported ideology, or on voting preferences. Thus, the prime is irrelevant to the key storylines reported here, and we mention it no further.
} 
Control Variables. To measure self-identification with political conservatism, participants completed the same Political Conservatism scale from Study 3 (alpha $=.95)$. All participants in Study 4 additionally completed measurements of age, biological sex assigned at birth, and the population size of the city in which they resided. Further, in Study $4 \mathrm{c}$ only, participants completed measurements of income and education level (see Online Supplement).

\section{Study 4 Results and Discussion}

Analyses for Study 4 as a whole are reported in Table 4 below, and disaggregated analyses for each sample separately are presented in the supplement accompanying this paper. As can be seen in the supplement, the pattern of results was consistent across samples.

\section{$\underline{\text { Table IV }}$}

Study 4: COVID Threat, Desired Restriction, and Desired Punishment Predicting Leftand Right-Wing Authoritarianism

\begin{tabular}{|c|c|c|c|c|}
\hline & \multicolumn{2}{|c|}{ Zero-Order } & \multicolumn{2}{|c|}{$\begin{array}{c}\text { Block } 2 \text { (Block } 1= \\
\text { Demographics and } \\
\text { Conservatism) }\end{array}$} \\
\hline & LWA & RWA & LWA & RWA \\
\hline Perceived COVID Threat & $.25 * * *$ & $-.28 * * *$ & $.15 * *$ & -.05 \\
\hline Desired Restriction & $.24 * * *$ & $-.21 * * *$ & $.16^{* *}$ & -.05 \\
\hline Desired Punishment & $.23 * * *$ & .02 & $.23 * * *$ & $.22 * * *$ \\
\hline
\end{tabular}


Zero-order standardized betas revealed that LWA was significantly positively related to Perceived COVID Threat (beta $=.25, p<.001$ ), Desire for Government Restriction $($ beta $=.24, p<.001)$, and Desire for Government Punishment (beta $=.23, p$ $<.001)$. Subsequent hierarchical regressions revealed LWA's relationship to all three variables remained significant at Block 2 when entering political ideology, age, sex, and resident city population at Block 1 (see Table 4).

RWA also showed a theoretically consistent pattern: As expected by the ideologically-loaded nature of COVID-related issues (see Conway et al., 2020), RWA showed generally the opposite pattern of LWA at zero-order. However, when controlling for ideology and demographic variables at Block 1, at Block 2 these relationships altered such that there was no relationship between RWA and COVID Threat or Restriction. Further, the RWA-Punishment relationship became significantly positive (indeed, with a similar effect size as the LWA relationship), suggesting that isolating the authoritarian part of right-wing authoritarianism yielded more desire for punishment (even on an issue that leans liberal).

Taken together, Study 4 corroborates and extends Study 3. Whereas Study 3 focused on sensitivity to ecological stressors at a very general level, Study 4 focused on threat perceptions and desired responses to a very specific stressor. Across both studies, threat sensitivity (and related measures) significantly predicted LWA.

This is not merely an artifact of the overlap of political ideology with COVID threat perceptions. As in Study 3, in Study 4 the threat-LWA relationship held when controlling for self-reported political ideology. Thus, there is something beyond ideology that accounts for the pattern in these studies. Consistent with the large literature on 
authoritarianism and threat for RWA and growing evidence for a similar relationship for LWA (Conway et al., 2019; Manson, 2020), the most likely interpretation is that it is the authoritarianism part of LWA that accounts for the relationship.

\section{Study 5}

Study 3 showed evidence that, on the exact same (and largely ideologicallyneutral) measures of threat, high LWA and RWA persons report similar levels of threat sensitivity above and beyond political ideology. Study 4 showed that LWA predicts perceived COVID threat above and beyond political ideology (and generally did so more than RWA, which is understandable given the potential ideological conflict high-RWA persons might have over the disease). Study 5 employed a different method of evaluating threat with complementary strengths and weaknesses. Specifically, for Study 5, we created separate, ideologically-balanced scales that attempt to tap into threat in a parallel fashion for conservatives and liberals (for an example with dogmatism, see Conway et al., 2016). In Study 5, we use this method by creating two different, ideologicallybalanced scales of the threat-related construct Belief in a Dangerous World (BDW; Altemeyer, 1998).

There is a long history of associating right-wing authoritarianism with Belief in a Dangerous World (BDW) and, indeed, much of the evidence for the threatauthoritarianism relationship is based on $B D W$ (e.g., Altemeyer, 1998; Crawford, 2017; Duckitt, 2001; Duckitt et al., 2002; Duckitt et al., 2010; Jost et al., 2003). However, many of the beliefs outlined on the well-used Belief in a Dangerous World scale are not ideologically neutral, and this ideological content makes a direct comparison with LWA scientifically challenging. As a result, we created a new BDW scale that, while keeping 
the same language about danger, pointed the participant towards ideological concerns of more import to liberals. We then followed the approach prior researchers have applied with other constructs (Conway et al., 2016; Conway et al., 2018; Conway et al., 2020) and used both the original $B D W$ (focused on conservative threats) and the new $B D W$ (focused on liberal threats) to predict both RWA and LWA. In all cases, we controlled for political ideology.

\section{Method}

Study 5 was pre-registered on the Open Science Framework and can be accessed at https://osf.io/m9vfn/?view_only=2d44e638028a435cb1867e35efd20350. All predictions were a priori.

Participants. Four hundred and twenty-one U.S. adults were recruited using Amazon's Mechanical Turk (MTurk). Study 5's sample had a mean age of 38, largely identified as Caucasian (82\%), held a fairly even split between males and females (49\% female), and was slightly left-leaning politically (4.3 on a political conservatism scale with 4.5 as the midpoint).

$\boldsymbol{L W A} \boldsymbol{R} \boldsymbol{W A}$ and Ideology. Participants were randomly assigned to receive either the RWA scale or the LWA scale. All participants also completed the same standard twoitem political conservatism scale as in Studies 1-4.

Belief in a Dangerous World: Conservative Version (BDWC). Participants were further randomly assigned to either the conservative or liberal Belief in a Dangerous World scale.

In the original conservative scale, some of the items emphasize ideological content more harmonious with a conservative ideological focus, such as the destruction 
of the world by God or the preponderance of crime. The presence of these items may further influence the context of other items that appear to be more ideologically neutral. Belief in a Dangerous World: Liberal Version (BDWL). Half of the participants completed a modified version of the $B D W$ scale designed to focus on threats in domains more harmonious with the ideological focus of liberals: Environmental concerns, lack of medical care, and fighting wars. This modified Belief in a Dangerous World Liberal scale inserted a new content domain for seven of the twelve items, such that it intentionally pointed the potential danger in the item to liberal content domains, while keeping the danger-related language the same.

An example will illustrate. A (reverse-scored) item from the original conservative Belief in a Dangerous World scale reads: "The 'end' is not near. People who think that earthquakes, wars and famines mean God might be about to destroy the world are being foolish." This item in the modified Belief in a Dangerous World Liberal scale was adapted to read "The 'end' is not near. People who think that increases in destructive natural phenomena mean global warming might be about to destroy the world are being foolish."

In this way, seven of the twelve items were adapted to direct the item towards liberal-focused content. However, the key language of the items that illustrated the belief that the world is dangerous (e.g., words that portray worsening conditions and an inherent susceptibility to danger) were left identical (or as identical as the context allowed) in all cases.

Consistent with Conway et al.’s (2016, Study 1) work on dogmatism, for the modified $B D W L$ scale, we kept five of the items in their original state. These items on the 
surface appeared more ideologically neutral (e.g., "If a person takes a few sensible precautions, nothing bad will happen to him or her. We do not live in a dangerous world") and yet for participants receiving the $B D W L$, these items were completed in the context of a scale clearly about liberal-leaning ideological threats.

The resulting $B D W L$ scale is as follows (bold words are those altered or inserted from the original scale):

It seems that every year there are fewer and fewer truly respectable people [who care about the environment], and more and more persons with no morals at all who threaten everyone else.

Although it may appear that things are constantly getting more [environmentally] dangerous and chaotic, it really isn't so. Every era has its problems, and a person's chances of living a safe, untroubled life are better today than ever before.

If our society keeps degenerating the way it has been lately, it's liable to collapse like a rotten log and everything will be in chaos.

Our society is not full of immoral and degenerate people who prey on decent people. News reports of such cases are grossly exaggerating and misleading.

The "end" is not near. People who think that increases in [destructive natural phenomenon mean global warming] might be about to destroy the world are being foolish.

There are many dangerous people in our society who will attack someone out of pure meanness, for no reason at all.

Despite what one hears about [a lack of medical care], there probably is just as much [good health care] now than there ever has been. 
Any day now, [environmental chaos and social] anarchy could erupt around us. All the signs are pointing to it.

If a person takes a few sensible precautions, nothing bad will happen to him or her. We do not live in a dangerous world.

Everyday, as our society becomes more [immoral], a person's chances of [dying due to unlawful wars or lack of proper medical care] go up and up.

Things are getting so bad, even a decent [person who respects their environment] can still become a victim of the senseless destruction of others.

Our country is not falling apart or rotting from within.

Inter-item reliability for the scale was satisfactory in both conditions (Belief in a Dangerous World Conservative alpha $=.87$; Belief in a Dangerous World Liberal alpha $=.81)$.

\section{Results and Discussion}

Table 5 presents results from Study 5 . As can be seen there, results suggest that both LWA and RWA are related to Belief in a Dangerous World, but that the nature of those relationships is danger-domain specific. Consistent with pre-registered predictions, zero-order relationships revealed that while RWA was significantly positively related to the standard BDWC scale that focused on threat content domains of more relevance to conservatives $($ beta $[98]=.63, p<.001, L C I=.49, U C I=.74)$, the LWA scale was significantly positively related to the BDWL that contained threat domains of more relevance to liberals $($ beta $[90]=.38, p<.001, L C I=.19, U C I=.54)$. Unexpectedly, LWA was also significantly negatively correlated with the conservative domain BDWC (see Table 5). 


\section{$\underline{\text { Table V }}$}

Study 5: Relationship Between Authoritarianism and Belief in a Dangerous World

\begin{tabular}{|c|c|c|c|c|}
\hline & \multicolumn{2}{|c|}{ Zero-Order } & \multicolumn{2}{|c|}{$\begin{array}{c}\text { Block } 2 \text { (Block } 1= \\
\text { Conservatism) }\end{array}$} \\
\hline & LWA & RWA & LWA & RWA \\
\hline \multicolumn{5}{|l|}{ Dangerous World Measure } \\
\hline Conservative Domains (Standard) & $-.34 * * *$ & $.63 * * *$ & -.14 & $.53 * * *$ \\
\hline Liberal Domains (Modified) & $.38 * * *$ & .12 & $.42 * * *$ & $.22 *$ \\
\hline
\end{tabular}

Table 5 also indicates that these relationships go beyond mere political ideology, thus representing something specific to authoritarianism: The key relationships between LWA-BDWL $($ beta $=.42, p<.001)$ and RWA-BDWC $($ beta $=.53, p<.001)$ remained significant when controlling directly for political ideology - indeed, the relationships between RWA/LWA and their respective counterpart BDW scale became descriptively more similar to each other when controlling for ideology. Further, the non-matching ideological correlations both shifted more positively, such that the LWA-BDWC correlation became non-significant, while the RWA-BDWL correlation became significantly positive (though still much lower descriptively than the RWA-BDWR correlation as expected). 
These results suggest that while authoritarians on both sides of the political spectrum show heightened sensitivity to threat, the kind of threat that is important differs for LWA and RWA. This effect is more than simply political ideology, but rather says something about authoritarianism specifically: The key effects hold when controlling for self-reported political ideology. By balancing the ideological content via scales with both liberal and conservative content and controlling for self-reported ideology, this offers additional support for the fact that authoritarianism on both the right and the left is related to threat concerns. Recall that the majority of the language - and all danger-related language - on the $B D W L$ was identical to the language on the $B D W C$.

It is important to remember that the relationship between Belief in a Dangerous World (Conservative Version) and RWA has been previously used by scientists to infer a threat-authoritarianism relationship on the right side of the political spectrum (e.g., Altemeyer, 1998; Crawford, 2017; Duckitt, 2001; Duckitt et al., 2002; Duckitt et al., 2010; Jost et al., 2003). Because we must use the same standard of evidence on both sides (Tetlock, 1994), it is similarly reasonable to interpret an $L W A-B D W L$ relationship as evidence for a threat-authoritarianism relationship on the left side of the political spectrum.

These results also reveal that this effect is stronger and more pervasive for authoritarianism on the right: The RWA effects were stronger overall, and RWA was a significant positive predictor of the liberal-content focused BDW scale when ideology was controlled for. Thus, while offering no support for an account that suggests danger concerns do not matter in producing authoritarianism on the left, they do suggest the 
possibility of asymmetric influence. We return to this issue below in the general discussion.

\section{Study 6}

Prior research suggests that, above and beyond political ideology, LWA uniquely predicts support of liberal candidates in two elections that were viewed as especially threatening, but did not do so in an election that was less threatening (Conway \& McFarland, 2019; Conway et al., 2020). However, while the authors of that work speculated that, consistent with models of authoritarianism, perceived threat from the candidate in power (e.g., Donald Trump) is the likely mechanism by which LWA operates, no research to date has directly reported measurements of threat from the government in power (see Conway \& McFarland, 2019; Conway et al., 2020). Study 6 used data from two samples collected five days apart in December 2019. In both samples, we evaluated the degree that LWA uniquely predicts perceptions that the thensitting U.S. president was threatening, and further tested an LWA $\rightarrow$ Threat $\rightarrow$ voting intentions path (note that the predictive voting power of authoritarian measurements was recently used as validity evidence for conservative authoritarianism; Nilsson \& Jost, 2020). Because both samples used nearly-identical measures and showed the same basic pattern, for the sake of brevity we consider them together.

\section{Method}

Participants. Six hundred and fifty U.S. adults were recruited using Amazon's Mechanical Turk (MTurk) as part of a larger project studying political beliefs. Of those, 533 completed all measurements relevant to Study 6, thus comprising our final sample.

$\boldsymbol{L W A} / \boldsymbol{R} \boldsymbol{W} A$ and Ideology. Participants were randomly assigned to receive either 
the RWA scale or the LWA scale. All participants also completed the same standard twoitem political conservatism scale used in prior studies, as well as measurements of biological sex assigned at birth and age.

Trump Threat Perception. Participants also completed two items of threat-based concerns about the U.S. presidential administration $(a l p h a=.94)$ : "When I think of Donald Trump, it makes me feel a sense of threat," and "When I think of Donald Trump, it makes me feel anxious for my country's future."

Voting Intent. Participants completed single-item measures of their intent to vote for the Democratic nominee (at that time, yet to be determined) in the upcoming 2020 election, and their intent to vote for Donald Trump in the upcoming 2020 election (we reverse-scored this item as Opposition to Trump).

\section{Results and Discussion}

Consistent with expectations, LWA was significantly positively related to Perceived Trump Threat at Block 2 (controlling for political ideology, biological sex assigned at birth, and age), beta [256] $=.18, p<.001$, whereas RWA was negatively related to Trump Threat at Block 2, beta [277] $=-.19, p<.001$.

Further, as visually illustrated in Figure 2, evidence revealed strong support (while controlling for political ideology) for an LWA $\rightarrow$ Perceived Trump Threat $\rightarrow$ Democratic Candidate Support Path, indirect effect $=.07(\mathrm{LCI}=.02, \mathrm{UCI}=$ $.13), p=.004$. Similarly, evidence revealed strong support for an LWA $\rightarrow$ Perceived Trump Threat $\rightarrow$ Oppose Trump Path, indirect effect $=.08(\mathrm{LCI}=.04, \mathrm{UCI}=.14), p=$ .003 . 
These results provide additional corroboration of the evidence linking LWA to threat. As before, they cannot be accounted for by political ideology: It is not merely that liberals felt Trump was more threatening (although liberals overwhelmingly did), but rather that authoritarian liberals were uniquely prone to believe Trump was threatening. Taken together with the evidence so far, this suggests wide grounds for believing that the LWA scale captures threat-sensitivity that is more than mere liberal ideology.

Importantly, Study 6 further demonstrates the practical utility of considering LWA as a construct in helping us better understand voting intent for the 2020 election. Specifically, high LWA persons' heightened sensitivity to threats from Trump accounts for part of why they were especially likely to vote for the democratic party (again, controlling for ideology and demographic variables).

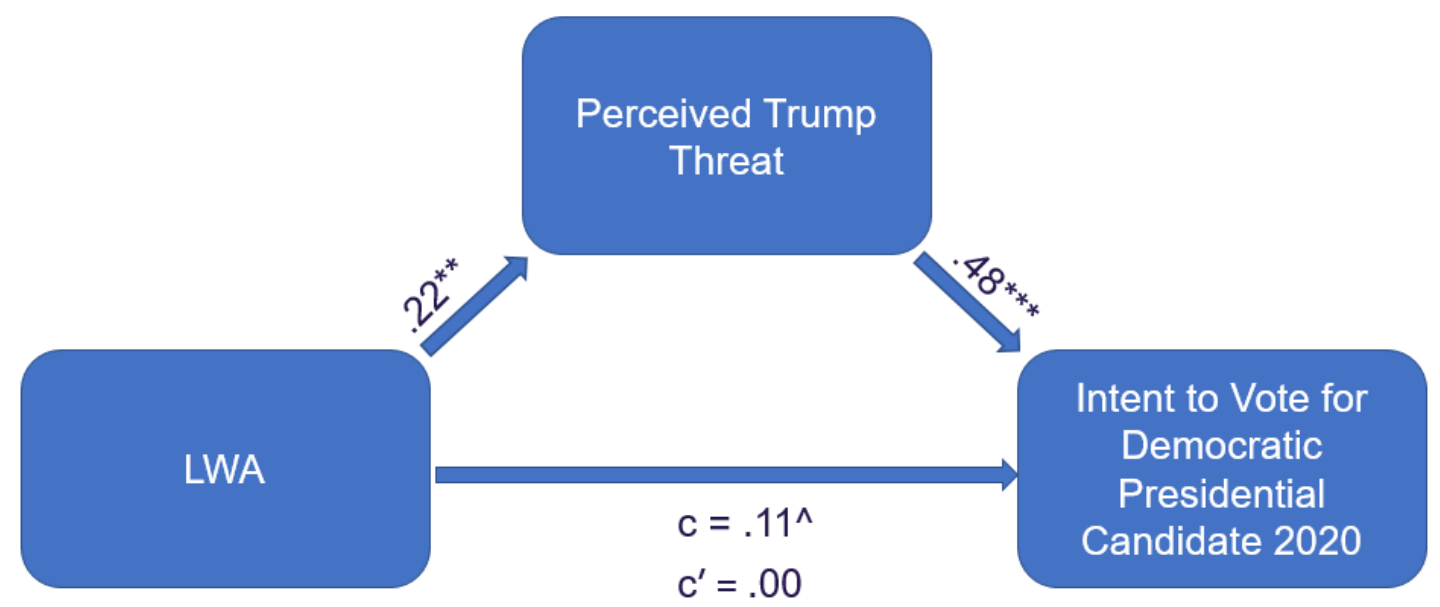

Figure II. Study 6: LWA $\rightarrow$ Perceived Trump Threat $\rightarrow$ Voting Intent

\section{Study 7}

Restrictive norms are central to conceptualizations of authoritarianism (e.g., 
Altemeyer, 1996; Duckitt et al., 2010; Feldman, 2003). Thus, we would expect that LWA would uniquely predict support for left-leaning norms that focused on restriction. Study 7 tested one such norm: Support for restrictive language norms, sometimes called "political correctness" norms (PC Norms).

\section{Method}

Participants. A sample of three hundred and fifty U.S. adults were recruited using Amazon's Mechanical Turk (MTurk).

LWA/RWA, Ideology, and Demographic Items. Participants were randomly assigned to receive either the RWA scale or the LWA scale. All participants also completed the same standard two-item political conservatism scale as in Studies 3-6, as well as measurements of age and biological sex assigned at birth.

Restrictive PC Norms Support. Participants completed four items concerning their support for restrictive communication norms (items and introduction were adapted directly from Conway et al's 2017 restrictive PC norms condition). The items were preceded by the following instructions:

Now, we would like to get your opinions on societal norms. In our modern society, we have norms that dictate that we refrain from saying negative things especially those things deemed as politically incorrect to say. These norms state that it is better to have rules that constrain us from anything that might sound toonegative or might be offensive to members of particular groups. We want to get your opinion on these norms.

Participants then completed the following four items: "I am in favor of norms (such as "Political Correctness" norms) that restrict what people in society can say about others, 
especially other groups," "I think norms restricting the negativity of communication have value," "I strongly oppose societal pressures to restrict what people are 'allowed' to say without retribution" (reverse-scored), and "In general, I believe strongly in the value of societal norms governing communication.” Inter-item reliability for the scale was satisfactory $($ alpha $=.85)$.

\section{Results and Discussion}

Consistent with expectations, LWA was significantly positively related to Restrictive PC Norm endorsement (standardized beta[171] $=.35, p<.001$ ), and this relationship remained significant even when accounting for political ideology, age, and biological sex assigned at birth at Block $2($ beta $=.19, p=.027)$. RWA was not significantly related to PC Norm endorsement at either Block 1 or Block 2. These results clearly offer additional support for our present purpose. Specifically, Study 7 shows that, above and beyond political ideology, LWA is predictive of a desire for society to have and to enforce restrictive communication norms. ${ }^{9}$

\section{Study 8}

Stereotypes and prejudice are typically associated with conservatives in general, and right-wing authoritarianism in particular (e.g., Jost et al., 2003). More recent research has suggested, however, that prejudice can occur on both sides of the political spectrum. For example, work has revealed that liberals show negative attitudes towards African

\footnotetext{
${ }^{9}$ Studies 6 and 7 also contained a manipulation of thinking about Trump: Half of the participants were assigned to write a brief paragraph about Trump at the beginning of the study, the other half to write about broccoli. This manipulation is not relevant to the purpose of the studies outlined here, and analyses withincondition across studies reveal essentially identical effect sizes for the key tests in both conditions. Thus we discuss this no further. Additionally, both Studies 5 and 6 contained other measurements not relevant to the primary storyline here - see supplemental materials.
} 
Americans when they believe they possess conservative attitudes such as religious fundamentalism (Chambers et al., 2013). Paralleling work on the unique contribution of right-wing authoritarianism to prejudice, newer work has tied left-wing authoritarianism to group attitudes by revealing that persons high in LWA are more likely to exhibit the equivalent of modern racism on a scale that targets Christian fundamentalists (Conway et al., 2018).

This prior work on LWA has been criticized for having "selected targets of prejudice that are rarely victims of prejudice in the US" (Saunders et al., 2020). To fill in this gap, Studies 8 and 9 apply the LWA framework to two groups that have historically been the target of prejudice: Religious African American persons and Jewish persons who support Israel.

In the current study, we draw on prior work suggesting that the presence of perceived conservative attitudes will cause liberals to show dislike of African Americans. One such attitude is religiosity (Chambers et al., 2013). This is important because, in the modern U.S., the large majority of African Americans are religious (for example, 77\% of African Americans believe that "the Bible is the Word of God"; Diamant, 2018). Thus, if LWA uniquely predicts negative attitudes towards religious African Americans beyond political ideology, this suggests its potential power in understanding prejudicial attitudes towards a large group of persons that have historically been the targets of prejudice in the U.S. Extrapolating from survey data, a cautious estimate of the number of African Americans who "believe in the Bible" is 30 million persons.

Similarly, Jews in the U.S. have historically been the targets of prejudice. The majority of modern Jewish Americans support the state of Israel, with estimates as high 
as $90 \%$ (Newport, 2019). Thus, if persons high in LWA show negative attitudes towards this group beyond political ideology, this suggests the unique contribution of LWA to potential prejudice on a large group of persons that have historically been the targets of prejudice. Extrapolating from survey data, a cautious estimate of the number of Jewish Americans who support Israel is 4 million persons.

\section{Method}

Participants. Two hundred and seventy-one U.S. adults were recruited using Amazon's Mechanical Turk (MTurk).

LWA/RWA, Ideology, and Demographic Items. Participants were randomly assigned to receive either the RWA scale or the LWA scale. All participants also completed the same standard two-item political conservatism scale as in Studies 3-7, as well as measurements of age, biological sex assigned at birth, and population of resident city.

Personal Group Favorability Ratings. All participants completed standard "feeling thermometer" measurements drawn from prior research (e.g., Dyrbye et al., 2019; Schaller et al., 2002) concerning their own personal views of particular groups. The directions preceding these ratings were as follows:

Please indicate below your responses to each group, where $1=$ your personal view is VERY UNFAVORABLE towards this group, $5=$ your personal view is neither favorable nor unfavorable towards this group, and $9=$ your personal view is VERY FAVORABLE towards this group. In each of these items, you are indicating your own personal view, not what anyone else believes.

Participants were then presented with six groups and rated each group on a 1-9 
feeling thermometer: Bible-believing men, Bible-believing women, Bible-believing African-American men, Bible-believing African-American women, Strong supporters of the nation of Israel's interests who are also Jewish men, and Strong supporters of the nation of Israel's interests who are also Jewish women.

Societal Attitudes. To distinguish their private views from their views of society (see Nosek, 2005; Schaller et al., 2002), all participants also completed responses to the same six target groups while considering, not their own views, but the views of society as a whole. This set was preceded by the following directions:

Please indicate below your responses to each group, where $1=$ society in general is VERY UNFAVORABLE towards this group, $5=$ society in general is neither favorable nor unfavorable towards this group, and $9=$ society in general is VERY FAVORABLE towards this group. In each of these items, you are NOT indicating your own personal view - rather, you are indicating what you think society in general believes.

The order with which participants completed the private versus societal measures was randomly assigned. Further, after each section (private or societal), participants were asked to indicate whether they had completed private or societal measures, and participants who answered incorrectly in either section were dropped.

\section{Results and Discussion}

As can be seen in Table VI, results overwhelmingly support the unique predictive validity of LWA for negative group attitudes towards African-Americans and Jews. When accounting at Block 2 for political ideology and the demographic factors, LWA predicted negative personal attitudes towards African-Americans who believed in the 
Bible and Jews who were supportive of Israel (all $p$ 's $<.001$ ). This occurred in spite of the fact that, as revealed in the bottom half of Table VI, there was, if anything, a positive relationship between LWA and participants' beliefs about societal views on these groups (although this relationship was generally non-significant once accounting for ideology and demographic factors).

As expected by theories of the ideology-prejudice relationship (e.g., Chambers et al., 2013), RWA was generally positively predictive of attitudes towards AfricanAmericans who believe in the Bible. RWA was also positively predictive of favorable attitudes towards Jews who support Israel, although these relationships became nonsignificant when accounting for ideology and demographic factors at Block 2. 


\section{Table VI}

Study 8: LWA and RWA Predicting Attitudes Towards African Americans and Jews

\begin{tabular}{|c|c|c|c|c|}
\hline & \multicolumn{2}{|c|}{ Zero-Order } & \multicolumn{2}{|c|}{$\begin{array}{l}\text { Block } 2 \text { (Block } 1= \\
\text { Demographics and } \\
\text { Conservatism })\end{array}$} \\
\hline & LWA & RWA & LWA & RWA \\
\hline \multicolumn{5}{|l|}{ Personal Group Favorability: } \\
\hline Bible-believing men & $-.63 * * *$ & $.62 * * *$ & $-.47 * * *$ & $.50 * * *$ \\
\hline Bible-believing women & $-.62 * * *$ & $.58 * * *$ & $-.51 * * *$ & $.48 * * *$ \\
\hline Bible-believing African-American men & $-.58 * * *$ & $.52 * * *$ & $-.48 * * *$ & $.37 * * *$ \\
\hline Bible-believing African-American women & $-.61 * * *$ & $.55 * * *$ & $-.51 * * *$ & $.45 * * *$ \\
\hline Strong supporters of Israel/men & $-.53 * * *$ & $.35 * * *$ & $-.43 * * *$ & .13 \\
\hline Strong supporters of Israel/women & $-.50 * * *$ & $.30 * * *$ & $-.39 * * *$ & .08 \\
\hline \multicolumn{5}{|l|}{ Societal Attitudes: } \\
\hline Bible-believing men & $.42 * * *$ & $-.25 * *$ & $.35 * * *$ & -.12 \\
\hline Bible-believing women & $.41 * * *$ & $-.17 *$ & $.38 * * *$ & -.00 \\
\hline Bible-believing African-American men & $.24 * * *$ & .09 & $.22^{\wedge}$ & .05 \\
\hline Bible-believing African-American women & $.21 * * *$ & .12 & $.18^{\wedge}$ & .17 \\
\hline Strong supporters of Israel/men & $.28 * * *$ & -.09 & $.20^{\wedge}$ & -.11 \\
\hline Strong supporters of Israel/women & $.29 * * *$ & .01 & $.26^{*}$ & .01 \\
\hline \multicolumn{5}{|c|}{$\begin{array}{l}\text { Notes: Total } N=271 . \text { LWA } N=137 ; \text { RWA } N=134 \text {. All metrics = standardized betas. } \\
* * * p<=.001 ; * * p<=.01 ; * p<=.05, \wedge p<=.10 \text {. Block } 2 \text { controls for political ideology, } \\
\text { age, biological sex assigned at birth, and population of resident city. }\end{array}$} \\
\hline
\end{tabular}

\section{Study 9}

Study 8 provided initial evidence that persons high in LWA are uniquely prone to negative attitudes towards persons in two groups historically the targets of prejudice: African-Americans and Jews. This LWA-negative attitude relationship occurs if certain characteristics of the groups - characteristics that describe the large majority of group members in each case (Diamant, 2018; Newport, 2019) - are made salient. 
Nevertheless, it is possible that the methods of Study 8 affected the outcome by presenting the content issue first, both across items ("Bible-believing men" was the first item, thus making "bible-believing" and not ethnicity salient) and within-item ("Biblebelieving" and "Supports Israel" were always first within-item, with ethnicity coming at the end). Study 9 directly accounted for this by providing conditions that, instead of first presenting the politically-relevant issue, presented the ethnicity first (e.g., "AfricanAmerican men" and not "Bible-believing men" appears first in this condition).

As we will see below, this manipulation did not impact the results, thus effectively ruling out a language presentation bias issue from Study 8 .

\section{Method}

Participants. one hundred and sixty-nine U.S. adults were recruited using Amazon's Mechanical Turk (MTurk).

LWA/RWA, Ideology, and Demographic Items. As in Study 8, Participants were randomly assigned to receive either the RWA scale or the LWA scale. All other covariates and measures were also identical to Study 8.

Personal Group Favorability and Societal Ratings. Half of the participants were randomly assigned to complete standard "feeling thermometer" measurements that were identical to Study 8 (Issue-First Condition). The other half (Ethnicity-First Condition) completed measurements that were conceptually identical, but differed in two respects. (1) Instead of the opening questions being about "Bible-Believing Men" and "Bible-Believing Women," they were replaced with "African American Men” and “African American Women.” (2) Language within-item was altered so that the ethnicity, and not the politically-relevant issue, came first. For example, "Bible-Believing African- 
American Women" became "African-American Women who believe in the Bible."

This same principle was applied to the societal ratings - participants in the Issue-

First Condition also received parallel issue-first societal ratings identical to Study 8 , whereas participants in the Ethnicity-First Condition received altered questions that were the same as those described for personal favorability ratings (only with societal content). All other aspects of Study 9 were identical to Study 8 .

\section{Results and Discussion}

All key results were essentially identical across both Ethnicity-First and IssueFirst conditions. ${ }^{10}$ As a result, for the sake of brevity, we collapse them here.

As can be seen in Table VII, results again overwhelmingly support the unique predictive validity of LWA for negative group attitudes. When accounting at Block 2 for political ideology and the demographic factors, LWA predicted negative personal attitudes towards African-Americans who believed in the Bible and Jews who were supportive of Israel in a manner descriptively and inferentially identical to Study 8 (all $p ’ \mathrm{~s}<.001)$.

Although there was more of a negative relationship between beliefs about societal attitudes and LWA than in Study 8, these results (in a manner identical to Study 8) generally became non-significant when controlling for ideology and demographics. Importantly for our purposes, both studies revealed a strong and consistent negative effect of LWA on private attitudes towards the two groups, with smaller (and generally

\footnotetext{
10 There was a descriptive tendency for RWA to be more positively associated with African-American and Jewish personal favorability scores in the Issue-First condition than in the Ethnicity-First condition. This makes sense and suggests part of the drop in effect size for RWA for Study 11 might have been due to the addition of the Issue-First condition. However, the general tenor of the RWA results remains the same across these conditions, and as our paper is focused primarily on LWA, we did not pursue this potential RWA interaction any further. The larger point is that the language context manipulation has no bearing on the key relationship reported here between LWA and negative group attitudes.
} 
non-significant) effects on beliefs about societal attitudes. In other words, these results clearly isolate this effect to the personal beliefs of our LWA participants - an effect that was consistently strong, significant, and negative - as opposed to their perceptions of what society at large believes.

As seen in Table VII, the results for RWA were in the same direction, but generally weaker (and at BLOCK 2, non-significant) than those for Study 8.

Taken together, Studies 8 and 9 demonstrate a consistent effect of LWA on personal attitudes towards two groups historically the targets of prejudice: AfricanAmericans and Jews. Persons high in LWA are more likely to have negative attitudes towards members of those groups that are described in terms consistent with the beliefs of the majority of the groups' members. This effect occurs even when the ethnicity, and not the issue, is initially made salient in the ratings. And - of vital importance - it occurs even when controlling for ideology and demographic factors. As in Studies 3-7, the results in Studies 8 and 9 reveal that there is something about certain kinds of liberals that goes beyond mere ideology. Consistent with decades of research on the authoritarianismprejudice link, that something is very likely best described as authoritarianism. 


\section{$\underline{\text { Table VII }}$}

Study 9: LWA and RWA Predicting Attitudes Towards African Americans and Jews

\begin{tabular}{|c|c|c|c|c|}
\hline & \multicolumn{2}{|c|}{ Zero-Order } & \multicolumn{2}{|c|}{$\begin{array}{l}\text { Block } 2 \text { (Block } 1= \\
\text { Demographics and } \\
\text { Conservatism) }\end{array}$} \\
\hline & LWA & RWA & LWA & RWA \\
\hline \multicolumn{5}{|l|}{ Personal Group Favorability: } \\
\hline Bible-believing African-American men & $-.65 * * *$ & $.26^{*}$ & $-.59 * * *$ & .20 \\
\hline Bible-believing African-American women & $-.64 * * *$ & $.25 *$ & $-.56 * * *$ & .20 \\
\hline Strong supporters of Israel/men & $-.50 * * *$ & $.19^{\wedge}$ & $-.35 * *$ & .09 \\
\hline Strong supporters of Israel/women & $-.52 * * *$ & $.22 *$ & $-.40 * * *$ & .11 \\
\hline \multicolumn{5}{|l|}{ Societal Attitudes: } \\
\hline Bible-believing African-American men & $-.25 *$ & $.27 * *$ & -.21 & $.30^{\wedge}$ \\
\hline Bible-believing African-American women & $-.27 *$ & $.29 * *$ & -.21 & $.27^{\wedge}$ \\
\hline Strong supporters of Israel/men & -.11 & -.01 & -.06 & .08 \\
\hline Strong supporters of Israel/women & -.14 & -.04 & -.11 & .08 \\
\hline \multicolumn{5}{|c|}{$\begin{array}{l}\text { Notes: Total } N=169 . \text { LWA } N=80 ; \text { RWA } N=89 . \text { All metrics }=\text { standardized betas. } \\
* * * p<=.001 ; * * p<=.01 ; * p<=.05, \wedge p<=.10 . \text { Block } 2 \text { controls for political ideology, } \\
\text { age, biological sex assigned at birth, and population of resident city. }\end{array}$} \\
\hline
\end{tabular}

\section{Study 10}

In their study on LWA, Conway and colleagues (2018) demonstrated that persons high in LWA showed higher levels of dogmatism, modern racism, and attitude strength in liberal-focused domains. However, these results have been criticized as potentially not representing anything beyond political ideology (Honeycutt \& Jussim, 2020). To deal with this criticism, we here re-analyze the data provided by their LWA participants to control for political ideology.

\section{Method}


Participants. For this re-analysis, we only focused on participants in the original two studies who completed the LWA questionnaire. As reported in Conway et al. (2018), for their Study 1, one hundred and seventy-eight undergraduates completed questionnaires for course credit. For their Study 2, one hundred and forty-seven participants were recruited from MTurk.

Measures. All participants completed the LWA scale. They further completed measurements of domain-specific dogmatism based on Rokeach's Dogmatism scale (adapted from Rokeach, 1960), an adapted Modern Racism scale that targeted religious minorities instead of ethnic minorities (adapted from McConahay, 1986), and a measurement of the strength of their attitudes about climate change (adapted from Conway et al., 2008; Conway et al., 2011).

\section{Results and Discussion}

Conway et al. (2018) reported the zero-order correlations between LWA and dogmatism, modern racism, and attitude strength (all significantly positive). To establish the level of unique contribution above and beyond political ideology, here we use their publically-available data to control for political ideology. When accounting for political ideology, results revealed that significant variance remained for LWA predicting Dogmatism in their Study 1 (standardized beta $=.29, p<.001$ ) and Study 2 (standardized beta $=.42, p<.001)$. Similarly, when accounting for political ideology, results revealed that significant variance remained for LWA predicting Modern Racism targeted at religious minorities in Study 1 (standardized beta $=.53, p<.001$ ) and Study 2 (standardized beta $=.62, p<.001$ ). However, although the relationships were still positive, the relationship between LWA and attitude strength became non-significant 
when accounting for political ideology in Study 1 (standardized beta $=.09$ ) and Study 2 (standardized beta $=.06)$.

Taken together, these results suggest that the majority of Conway et al's original work - like all of the work presented here in Studies 3-9 - shows LWA predicts key phenomena above and beyond political ideology. No construct will show unique predictive validity in every instance; but the overwhelming tenor of the combined work presented here reveals that LWA is a unique predictor of the kind of phenomena that conceptually an authoritarianism measure should predict.

\section{Study 11: Within-Group Validity Tests}

Across eight studies using Conway et al's (2018) LWA measure, we have demonstrated the predictive power and theoretical relevance of LWA as a construct. In each case, we have controlled for participants' level of political ideology (as well as any available demographic factors that were measured in each study). This suggests there is something beyond mere ideology that explains high-LWA persons' increased sensitivity to threat (Studies 3-6), their support for restrictive communication norms (Study 7), their negative group attitudes (Studies 8 and 9), and their dogmatism, group bias, and attitude strength (Study 10).

Of course, as noted in the introduction, measuring authoritarianism is tricky because, almost by definition, people are authoritarian to a specific authority figure or group. That means that all authoritarian measures contain content related to the specific group (e.g., the "right-wing" in right-wing authoritarianism) and to authoritarianism (e.g., the "authoritarianism” in right-wing authoritarianism; Conway, 2020). Left-wing 
authoritarianism shares this measurement challenge with all other measurements of authoritarianism.

As a result, it is an important measurement obstacle to isolate the "authoritarian" part of "left-wing authoritarianism." As noted earlier, there are multiple conceptual methods to do this. One method involves using parallel scales to test competing kinds of authoritarianism content/targets simultaneously so as to better understand the entire construct of authoritarianism. A second method involves controlling directly for political ideological content/targets, thus isolating the "authoritarian" part of "[content domain] authoritarianism." We have applied both of those methods thus far in the present work. A further, straightforward method for separating out ideology from authoritarianism that has complementary strengths and weaknesses is to perform withinideological group analyses (see Wronski, 2018, for an example). In other words, one way to separate liberal authoritarians from liberal non-authoritarians is to look only at liberals. To accomplish this, for Studies 3-10, we performed further analyses that analyzed all key LWA effects by looking only at persons who scored on the liberal side of the 1-9 ideology scale (because the scale is anchored by $1=$ liberal and $9=$ conservative, for these analyses, we only included persons scoring below the midpoint). For ease of understanding, when necessary we reverse-scored (and reverse-named) variables so that positive numbers always meant the expected LWA effect. We also combined variables in some cases to make the results easier to digest (using the disaggregated variables yielded an identical set of results).

Results are presented in Table VIII. As can be seen there, in the vast majority of cases, the within-group analyses in the last column corroborated whole-sample analyses 
in the preceding column (all whole-sample analyses in the table control for political ideology + any demographic variables measured in that study). As would be expected in any such large analyses, some significant whole-sample effects became non-significant within-group, and some non-significant whole-sample effects became significant withingroup (e.g., attitude strength). However, all analyses of each type showed effects in the same direction, and the vast majority were significant in both kinds of analyses. This can be easily seen by the evaluating the average effect sizes across studies, which are very similar for both whole-sample (average beta $=.32$ ) and within-group (average beta $=.37$ ) analyses.

These analyses suggest that when we compare liberals to other liberals with different degrees of authoritarianism, we still (in the main) get the conceptually-expected relationships in this large array of studies. This provides additional triangulating evidence that the left-wing authoritarian is more of a reality than a myth. ${ }^{11}$

\footnotetext{
${ }^{11}$ We additionally re-computed the indirect path analyses from Study 6 within-group and found the exact same set of results reported on the whole sample. Specifically, looking only at liberals from Study 6 revealed support for an LWA $\rightarrow$ Perceived Trump Threat $\rightarrow$ Democratic Candidate Support Path, indirect effect $=.08(\mathrm{LCI}=.02, \mathrm{UCI}=.17), p=.014$. Similarly, within-group evidence revealed support for an LWA $\rightarrow$ Perceived Trump Threat $\rightarrow$ Oppose Trump Path, indirect effect $=.07(\mathrm{LCI}=.02, \mathrm{UCI}=.15), p=$ .018 .
} 
$\underline{\text { Table VIII }}$

Study 11: LWA Effects Both Whole-Sample and Within-Group (Liberals-Only)

\section{Whole-Sample LWA \\ Liberals-Only \\ LWA}

$\begin{array}{ll}.15 * * * & .10 * * * \\ .15 * * & .09 \\ .16 * * & .13 * \\ .23 * * * & .09 \wedge \\ .42 * * * & .64 * * * \\ .18 * * * & .25 * * \\ .19 * * * & .08 \\ .50 * * * & .54 * * * \\ .58 * * * & .67 * * * \\ .42 * * * & .37 * * * \\ .39 * * & .47 * * \\ .29 * * * & .39 * * * \\ .42 * * * & .40 * * * \\ .53 * * * & .60 * * * \\ .62 * * * & .64 * * * \\ .09 & .39 * * * \\ .06 & .41 * * * \\ .32 * * * & .37 * * *\end{array}$

Perceived Ecological Threat (Study 3)

COVID Threat Sensitivity (Studies 4)

Desired Restriction (Study 4)

Desired Punishment (Studies 4)

Belief in a Dangerous World (Study 5)

Trump Threat Sensitivity (Study 6)

Restrictive Communication Norms (Study 7)

Negative Views/African Americans (Study 8)

Negative Views/African Americans (Study 9)

Negative Views/Jews (Study 8)

Negative Views/Jews (Study 9)

Dogmatism (Study 10a)

Dogmatism (Study 10b)

Modern Racism/Relig. Minorities (Study 10a)

Modern Racism/Relig. Minorities (Study 10b)

Attitude Strength (Study 10a)

Attitude Strength (Study 10b)

AVERAGE EFFECT SIZE

Notes: All metrics $=$ standardized betas. ${ }^{* * *} p<=.001 ; * * p<=.01{ }^{*} p<<=.05, \wedge p<=.15$. Across-Group LWA correlations always control for political ideology (every study) + any available demographic factors. All metrics reverse-scored/named as necessary so that positive correlations always equal the conceptually-expected direction for LWA.

\section{Study 12}

Much of the debate around LWA has centered only on authoritarianism in Western democracies. However, this WEIRD group of participants is not representative of the whole earth's population (Henrich et al., 2010), and much more work is needed on individual differences in particular in non-WEIRD samples (Cooper, 2016). As a result, it is important to evaluate the LWA question in samples beyond the U.S. This is especially 
true as there are reasons to expect that left-wing authoritarianism might be more prominent in non-Western contexts (e.g., De Regt et al., 2011; Jost et al., 2003; McFarland et al., 1992, 1993; Todosijević, 2005; Todosijević \& Enyedi, 2008).

One method of evaluation is to find validated comparative measurements across nations that attempt to measure both ideological self-identification and authoritarianism with as little measurement cross-contamination as possible. This requires a left-right selfidentification measurement that does not contain potential authoritarian content (see Houck \& Conway, 2019, for discussion) and an authoritarianism measurement that does not contain explicit ideological content.

While perfectly non-contaminated measurements are essentially impossible especially for a domain-specific measurement like authoritarianism (Conway, 2020) some measurements are more bias-free than others. One method of reducing the ideological content in authoritarianism measures is to use generic statements that focus on governmental leadership in a non-partisan way (e.g., Sprong et al., 2019). It is worth noting that these measurements are not ideological content-free; at a minimum, they contain implied ideological content to participants. For example, when participants are asked to report agreement with the statement "Our country needs a strong leader right now" (e.g., Sprong et al., 2019), it very likely matters to participants whether or not they imagine a person whose political views they agree with is the strong leader in question. If conservative persons imagine that the strong leader in question is liberal, it would very likely change their answers to the question (compared to believing that the strong leader was conservative). If liberal persons imagine that the strong leader in question is 
conservative, it would very likely change their answers (compared to believing that the strong leader was liberal).

Thus, such generic language does not produce ideological content-free measurements. However, in a large multi-national study, it does have the advantage of allowing participants themselves across a large number of political contexts to selfdetermine their own views of leadership and ideology. If this kind of item were collected in only one context, it is likely just as ideologically biased as any other kind of measure. However, when averaged across multiple contexts that vary in the ideological bent of the political leadership (and thus likely vary in the way the item maps on to participant beliefs about the ideological bent of the hypothetical person in the question), it allows for a more (though hardly perfect) ideological content-free test.

In Study 12, we use a generic measurement of governmental authoritarianism similar to that in Sprong et al. (2019) to estimate the worldwide effect of ideology on authoritarianism. This authoritarianism measure was completed in Wave 6 of the World Values Survey (WVS; Inglehart et al., 2014). Specifically, over 66,000 participants across 54 nations completed a standard Political identification (left-right) item (e.g., Jost et al., 2003; Sprong et al., 2019; Nilsson \& Jost, 2020) and a standard Authoritarian Governance endorsement questionnaire (e.g., Ariely \& Davidov, 2010; Miller, 2017; Malka, Lelkes, Bakker, \& Spivack, 2020). The political identification item allows participants to self-identify on the left or right, offering no direct method overlap with authoritarianism. Further, the authoritarianism scale does not directly offer clearly leftright political positions, but rather asks participants about the degree that they would support various authorities countermanding normal governmental processes. Thus, 
measured in contexts with varying levels of governmental ideologies, these

measurements help define the relationship between authoritarianism and ideology across 54 nations on 5 continents in a way that minimizes ideological cross-contamination.

Prior research across twenty-eight nations (Sprong et al., 2019) using a generic authoritarian leadership measurement (similar to that used in the present study) found a small-to-moderate association between authoritarianism and conservative political orientation $(r=.20)$. Although not designed to specifically test the relationship between authoritarianism and conservative political orientation, this study nonetheless provides a useful starting point. However, it has a limited number of nations and does not have a strong sampling of nations that might be especially prone historically to LWA (e.g., Eastern Europe and former Soviet Republics). In the present study, we nearly doubled the nation-level sample size and included more areas for which LWA might be more manifest. ${ }^{12}$ We used two different approaches - multilevel modeling and standardized within-country analyses - to estimate the worldwide effects of ideology on authoritarianism.

For reasons outlined by other researchers (Jost et al., 2003; Conway et al., 2020; Malka et al., 2020) and consistent with prior data (Sprong et al., 2019), we expected that

\footnotetext{
12 In a separate study, Napier and Jost (2008) had 19 democratic (mostly Western) countries from Wave 4 of the World Values Survey. However, not only does their study specifically only focus on a region of the world where one would expect LWA to be lowest (Western democracies) and thus does not advance our knowledge very far beyond WEIRD samples, their measurement of authoritarianism was poor on multiple levels. In addition to including only dichotomous responses, it was loaded with conservative content issues, such as those involving obedience to parents and approaches to single parenting. It further included two items related to general cynicism/trust that are conceptually orthogonal to belief in specific authority figures. In spite of these reasons to distrust the results as a biased approach to the question of LWA, they nonetheless found generally only small-to-moderate effect sizes for the conservatism-authoritarianism relationship - in the exact region of the world where effect sizes for RWA should be highest. As a result, even taken at face value, they largely corroborate the message of the paper here.
} 
in general, there would be a positive association between conservative ideological identification and authoritarianism across the world. However, we also expected that this effect would be moderated by the national political context, such that some nations would show less evidence of purely conservative authoritarianism. For example, we expected that this relationship between conservatism and endorsement of government authoritarianism would be less positive in contexts that had a history of influence by leftwing authoritarian governments (e.g., De Regt et al., 2011; Jost et al., 2003; McFarland et al., 1992, 1993; Todosijević, 2005; Todosijević \& Enyedi, 2008). Study 12 thus provides novel evidence to more clearly evaluate the state of world authoritarianism on a comparable set of authoritarianism and ideology questionnaires in 54 countries. To our knowledge, this is by far the largest study on world-wide authoritarianism to date.

\section{Method}

Participants. For Wave 6 of the WVS, 66,974 participants across 54 nations completed Ideology and Authoritarianism questionnaires.

Ideological Conservatism. Participants were asked to position themselves on a 1-10 political left-right continuum, where $1=$ "Left" and $10=$ "Right." (Participants who responded with answers not placing themselves on the continuum were dropped).

Authoritarianism. Participants completed a three-item measure of endorsement of Authoritarian Governance that has been used in prior research to measure authoritarianism (e.g., Ariely \& Davidov, 2010; Miller, 2017; Malka et al., 2020). These items ask participants the degree that they value "Having a strong leader who does not have to bother with parliament and elections," "Having experts, not government, make decisions according to what they think is best for the country," and "Having the army 
rule." The items were on a scale from 1-4 where 1 = more agreement; as a result, we reversed-scored them and averaged them into a single Authoritarianism measure in a manner identical to prior research (e.g., Ariely \& Davidov, 2010; Miller, 2017; Malka et al., 2020). (Participants who responded with answers not placing themselves on the continuum were dropped). ${ }^{13}$

Western Democracies Versus Eastern Europe. To evaluate cross-cultural differences, we further compared the ideology-authoritarianism relationship across available Western democracies (defined in the typical manner as the EU15 plus Australia, Canada, New Zealand, Norway, Switzerland, and the United States; see Malka et al., 2020) and a region long influenced by more authoritarian left-wing ideology: Eastern Europe (see INSOL, 2020) and/or the former Soviet Republics (taken together, in our sample this list includes Bulgaria, Czech Republic, Estonia, Hungary, Latvia, Lithuania, Moldova, Poland, Kosovo, Moldova, Romania, Russia, Serbia, Slovenia, Kazakhstan, Kyrgyzstan, Tajikistan, Turkmenistan, Uzbekistan, Armenia, Azerbaijan, Georgia, and Ukraine).

\section{Results}

Multilevel Analyses. We followed standard practices for Multilevel Analyses (e.g., Lorah, 2018; Sprong et al., 2019). Specifically, we used $R$ (R Core Team, 2014) to estimate multilevel models with the lme4 package (Bates et al., 2015). Our primary model (Model 2) predicted authoritarianism from ideology nested within countries.

\footnotetext{
${ }^{13}$ While none of these items is entirely ideologically-free, of these three items, the most clearly ideologically-free item is item one (about a desire for a strong leader). Thus, we further computed all analyses on this item only. Those analyses are identical, both descriptively and inferentially, as those reported for the whole scale.
} 
In Model 1, we first estimated the effect of our level 2 predictor (group: country) on authoritarianism. This predictably showed that nations differed from each other in their levels of authoritarianism, $I C C=.18, p<.001$. In Model 2, we then added our level 1 predictor (conservative ideology) to the level 2 predictor (country). Consistent with prior researchers' assertions about the general right-leaning nature of authoritarianism (e.g., Conway et al., 2020; Napier \& Jost, 2008; Sprong et al., 2019), this multilevel analysis revealed a positive relationship between conservative ideology and authoritarianism worldwide, beta $=.01, p<.001$. However, this relationship is very small and, as we will see below, within-country analyses clearly showed much variability across the world in the ideology-authoritarianism relationship.

Within-country analyses. A second (and related) method of evaluating the worldwide status of the ideology-authoritarianism relationship involves performing within-country analyses. For these analyses, both ideology and authoritarianism scales were first standardized within-country. As a result, any reported summary relationships represent the average within-country effect and thus directly control for across-country mean differences.

Results of within-country analyses are presented in Table IX. In that table, positive betas between authoritarianism and conservative ideology indicate a right-wing authoritarian leaning, while negative betas between authoritarianism and ideology indicate a left-wing authoritarian leaning (a beta of zero means that ideology and authoritarianism are unrelated, and thus the nation does not show a propensity towards either right-wing or left-wing authoritarianism on average). 
First, results averaged across nations were consistent with the Multilevel Modeling analyses: There was a small, but statistically significant, positive relationship between authoritarianism and conservative ideology worldwide, beta[66974] $=.03, p<$ .001. Thus, two different methods of estimating the worldwide effect of ideology on authoritarianism validated prior researchers' assertions that authoritarianism tends to be right-leaning (e.g., Conway et al., 2020; Napier \& Jost, 2008; Sprong et al., 2019).

However, not only was this relationship negligibly small, within-country analyses clearly showed much variability across the world in the ideology-authoritarianism relationship. As Table IX reveals, many nations - particularly those in Western Europe and South America - showed positive and statistically significant relationships between political conservatism and authoritarianism. However, as the bottom portion of Table IX reveals, many nations showed positive and statistically significant relationships of authoritarianism with political liberalism (as indicated by the negative relationships between the political conservatism scale and authoritarianism measurement).

Importantly, Table IX also reveals that these differences across nations in their propensity for authoritarianism to lean left or right are not likely an artifact of mean or SD differences across nations. Indeed, using nation as the unit of analysis $(n=54)$, the correlations between the ideology-authoritarianism beta and (a) country-level mean authoritarianism, (b) country-level SD for authoritarianism, (c) country-level mean ideology, and (d) country-level SD for ideology were all non-significant ( $r$ 's range from .25 to .09$)$, and that was also true if one considers the ideology-authoritarianism effect as an absolute value ( $r$ 's range from -.15 to .11). These additional results suggest there is 
real (and not artifactual) variability across countries in their likelihood of showing a conservatism-authoritarianism link. ${ }^{14}$

To understand part of this variability, we compared Western democracies with a region long influenced by more authoritarian left-wing ideology (Eastern Europe and former Soviet Republics). Specifically, after standardizing both authoritarianism and ideology within-nation, we ran a regression with National Context (Western Democracies versus Eastern Europe/Former Soviet Republics) and Ideology predicting Authoritarianism. Consistent with expectations, a National Context X Ideology interaction emerged (interaction beta $[22,673]=-.10, \mathrm{UCI}=-.13, \mathrm{LCI}=-.07, p<$ $.0001) .{ }^{15}$ This interaction resulted from a significantly positive relationship between conservatism and authoritarianism for those living in Western democracies (beta $=.09, p$ $<.0001$ ), but little to no relationship for those living in Eastern Europe/Soviet Republics $($ beta $=-.01, p=.14)$.

\section{Discussion}

These results reveal that authoritarianism is present on both the right and the left side of the political spectrum around the world. Using two different methods of estimating the average effect across 54 nations (and over 66 thousand persons), we found that the overall relationship between conservative ideology and desire for authoritarian

\footnotetext{
${ }^{14}$ Bolstering this case, we further divided persons up categorically into those that leaned left (below the midpoint of the scale) and those that leaned right (above the midpoint of the scale). As in Conway et al. (2018), analyses with this categorical variable suggests that our findings are not likely due to a correlational sleight-of-hand that is driven by generally higher levels of conservatism world-wide. Indeed, not only is this sample only slightly right-leaning (ideology scale mid-point $=5.5$; worldwide $M=5.66$ ), making such an alternative explanation unlikely, but also the highest level of authoritarianism in the world in this sample occurred for liberals in Egypt (Egypt Liberal Authoritarianism $M=3.64$; worldwide Authoritarianism $M=$ 2.32).

${ }^{15}$ This interaction remained significant (and in the same direction) when using the categorical left/right distinction as the ideology measurement $(F=9.98, \mathrm{p}<.002)$.
} 
government is very small. Further, in many nations, authoritarians were significantly more likely to occur on the left side of the political spectrum (see the bottom portion of Table IX). It is noteworthy that a right-leaning correlation between ideology and authoritarianism has been interpreted as evidence of right-wing authoritarianism (Nilsson \& Jost, 2020); thus, applying an equal and fair scientific standard, it is reasonable to interpret a left-leaning correlation between ideology and conservatism as evidence of leftwing authoritarianism. Given this, the left-leaning relationships reported at the bottom of Table IX suggest clear (and statistically significant) evidence for left-wing authoritarianism in multiple nations. Additionally, the conservatism-authoritarianism relationship is stronger on average in contexts where one might expect it to be stronger (Western democracies), and weaker on average in contexts where one might expect it to be weaker (Eastern Europe/former Soviet Republics).

The relationship between a desire for authoritarian government and ideology in each nation is doubtless influenced by a complicated and ever-changing interplay of the sitting government's ideology, the history of left-wing (versus right-wing) authoritarian movements in a nation, ongoing cultural movements related to authoritarianism on each side of the political spectrum, and nation-level stressors. It is beyond the scope of Study 12 to pursue that more complicated set of factors in depth. Our purpose is less complex but no less important: At a minimum, these results cast doubt on any explanation that leaves left-wing authoritarianism out of the world equation. In corroboration with Studies $1-11$, they more generally suggest that left-wing authoritarianism is more of a reality than a myth. 
$\underline{\text { Table IX }}$

Study 12: Individual-level Conservative/Liberal Ideology Predicting Individual-level Authoritarianism within Nations

\begin{tabular}{|c|c|c|c|c|c|c|}
\hline Nation & $n$ & $\begin{array}{l}\text { ID-Auth } \\
\text { Beta }\end{array}$ & $\begin{array}{l}\text { Ideology } \\
\text { Mean }\end{array}$ & $\begin{array}{l}\text { Ideology } \\
\text { SD }\end{array}$ & $\begin{array}{l}\text { Auth. } \\
\text { Mean }\end{array}$ & $\begin{array}{l}\text { Auth. } \\
\text { SD }\end{array}$ \\
\hline Yemen & 1250 & $.29 * * *$ & 5.7 & 2.5 & 2.3 & 0.7 \\
\hline Netherlands & 1610 & $.21 * * *$ & 5.5 & 2.0 & 2.0 & 0.5 \\
\hline Argentina & 790 & $.20 * * *$ & 5.5 & 1.8 & 2.1 & 0.7 \\
\hline Chile & 701 & $.19 * * *$ & 5.1 & 2.0 & 2.1 & 0.7 \\
\hline Spain & 991 & $.18 * * *$ & 4.8 & 1.9 & 2.1 & 0.6 \\
\hline Uruguay & 833 & $.18 * * *$ & 4.7 & 2.5 & 2.1 & 0.6 \\
\hline Morocco & 197 & $.16^{*}$ & 5.5 & 2.3 & 2.2 & 0.9 \\
\hline Armenia & 1002 & $.12 * *$ & 5.7 & 2.5 & 2.4 & 0.7 \\
\hline Columbia & 1242 & $.11 * * *$ & 6.2 & 2.4 & 2.5 & 0.6 \\
\hline Iraq & 976 & $.10 * * *$ & 6.2 & 2.4 & 2.4 & 0.6 \\
\hline Cyprus & 824 & $.09 * *$ & 5.2 & 2.7 & 1.9 & 0.7 \\
\hline Nigeria & 1759 & $.09 *$ & 5.7 & 2.5 & 2.4 & 0.7 \\
\hline Sweden & 1118 & $.08 * *$ & 5.4 & 2.5 & 1.9 & 0.7 \\
\hline South Korea & 1187 & $.08 * *$ & 5.4 & 2.1 & 2.2 & 0.5 \\
\hline Malaysia & 1300 & $.08 * *$ & 6.6 & 1.9 & 2.5 & 0.7 \\
\hline Germany & 1829 & $.07 * *$ & 5.0 & 1.8 & 1.9 & 0.6 \\
\hline Belarus & 1476 & $.07 * *$ & 5.4 & 1.6 & 2.2 & 0.5 \\
\hline Pakistan & 1172 & $.07 *$ & 7.4 & 2.0 & 2.7 & 0.6 \\
\hline Rwanda & 1527 & $.06^{*}$ & 5.4 & 1.9 & 2.3 & 0.6 \\
\hline Zimbabwe & 1499 & $.05^{*}$ & 5.3 & 2.7 & 2.0 & 0.6 \\
\hline Slovenia & 681 & $.07^{\wedge}$ & 5.1 & 2.2 & 2.1 & 0.5 \\
\hline Mexico & 1903 & $.04^{\wedge}$ & 6.2 & 2.7 & 2.6 & 0.5 \\
\hline Kazakhstan & 1500 & .04 & 6.2 & 2.2 & 2.3 & 0.6 \\
\hline Kyrgyzstan & 1461 & .03 & 6.5 & 2.3 & 2.7 & 0.6 \\
\hline Lebanon & 820 & .03 & 6.4 & 2.2 & 2.7 & 0.7 \\
\hline Libya & 1393 & .03 & 5.9 & 2.7 & 2.5 & 0.7 \\
\hline South Africa & 3003 & .02 & 6.3 & 2.1 & 2.6 & 0.8 \\
\hline United States & 2136 & .02 & 5.8 & 2.0 & 2.0 & 0.7 \\
\hline India & 3329 & $.02^{\wedge}$ & 5.7 & 2.3 & 2.7 & 0.8 \\
\hline Taiwan & 1125 & .02 & 4.6 & 1.9 & 2.4 & 0.6 \\
\hline Romania & 1082 & .02 & 5.7 & 2.7 & 2.8 & 0.7 \\
\hline Philippines & 1187 & .02 & 6.8 & 2.7 & 2.5 & 0.8 \\
\hline Brazil & 1199 & .01 & 5.3 & 2.8 & 2.7 & 0.6 \\
\hline Ghana & 1552 & .01 & 5.4 & 2.7 & 1.9 & 0.6 \\
\hline Japan & 1674 & .01 & 5.6 & 1.9 & 1.9 & 0.6 \\
\hline Peru & 1009 & .00 & 5.5 & 2.2 & 2.5 & 0.6 \\
\hline Haiti & 1940 & -.01 & 2.7 & 2.4 & 1.9 & 0.6 \\
\hline
\end{tabular}


Left-Wing Authoritarianism 75

$\begin{array}{lllllll}\text { Turkey } & 1368 & -.01 & 6.4 & 2.4 & 2.4 & 0.8 \\ \text { Australia } & 1404 & -.02 & 5.3 & 2.0 & 1.9 & 0.6 \\ \text { Ecuador } & 1139 & -.03 & 5.6 & 2.5 & 2.4 & 0.6 \\ \text { Georgia } & 778 & -.03 & 5.6 & 2.2 & 2.2 & 0.7 \\ \text { Palestine } & 720 & -.03 & 6.0 & 2.3 & 2.4 & 0.7 \\ \text { Ukraine } & 1500 & -.03 & 5.5 & 1.9 & 2.4 & 0.6 \\ \text { Poland } & 741 & -.03 & 5.5 & 2.3 & 2.3 & 0.5 \\ \text { Russia } & 1441 & -.04^{\wedge} & 5.4 & 2.1 & 2.5 & 0.6 \\ \text { Tunisia } & 696 & -.06^{\wedge} & 5.6 & 1.8 & 2.6 & 0.8 \\ \text { Algeria } & 1041 & -.08^{\wedge} & 6.0 & 2.1 & 2.0 & 0.8 \\ \text { Trinidad and Tobago } & 561 & -.08^{\wedge} & 6.4 & 2.4 & 1.8 & 0.7 \\ \text { Hong Kong } & 974 & -.08^{* *} & 5.4 & 1.7 & 2.1 & 0.6 \\ \text { Thailand } & 1187 & -.09^{* *} & 5.9 & 2.2 & 2.1 & 0.7 \\ \text { Azerbaijan } & 991 & -.10^{* *} & 5.9 & 2.0 & 2.2 & 0.6 \\ \text { Uzbekistan } & 777 & -.19^{* * *} & 6.5 & 2.1 & 2.5 & 0.9 \\ \text { Estonia } & 1254 & -.16^{* * *} & 5.4 & 1.9 & 2.1 & 0.6 \\ \text { Egypt } & 1523 & -.22^{* * *} & 6.1 & 2.3 & 3.5 & 0.6 \\ \text { TOTAL } & \mathbf{6 6 9 7 4} & \mathbf{. 0 3 * * *} & 5.7 & 2.4 & 2.3 & 0.7\end{array}$

Notes: ID-Auth Beta = standardized beta for conservative ideology-authoritarianism relationship; both measures standardized within-nation. $* * * p<=.001 ; * * p<=.01 ; * p<=$ $.05, \wedge p<=.10$. For ID-Auth Beta, Positive scores = right-wing authoritarianism more prevalent; negative scores $=$ left-wing authoritarianism more prevalent. Means and SDs are unstandardized scores.

\section{General Discussion}

Is left-wing authoritarianism a viable construct that predicts important real-world phenomena? Across twelve studies spanning over 8,000 participants in the U.S. and over 66,000 participants worldwide, our data consistently reveal the answer is yes. These data reveal that (1) both liberal and conservative American participants identify a large number of left-wing authoritarians in their everyday lives (Study 1), and (2) both liberal and conservative participants rate a common Left-Wing Authoritarianism scale as measuring authoritarianism (Study 2). Further, this same LWA scale consistently predicts key phenomena that major authoritarianism theories suggest it should predict, including (3) threat sensitivity (Studies 3-6), (4) restrictive communication norms (Study 7), (5) 
negative ratings of minority groups (Studies 8-10), and (6) dogmatism (Study 10).

Further, we used multiple methods to help overcome the double-barreled measurement problem inherent in any authoritarianism measurement, including controlling directly for ideology (Studies 3-10), performing analyses only on liberals (Study 11), and including a more generic measurement of authoritarian leadership across numerous national contexts (Study 12). Each of these approaches has offsetting strengths and weaknesses, and yet they all point to the same conclusion: This wide array of triangulating evidence provides consistent support for the idea that left-wing authoritarianism is indeed a widespread everyday reality.

Below, we place this array of evidence into the existing literature on authoritarianism and ideology, discuss limitations of our work, and offer a brief set of concluding thoughts.

\section{The Authoritarianism Debate}

The present studies have multiple implications for the ongoing debate about the nature of authoritarianism. We here highlight two: (1) LWA is not merely about ideology, and (2) LWA, far from muddying the authoritarianism waters, actually provides insight that helps us better understand authoritarianism in the bigger picture.

LWA measurement is not merely an ideology measurement. Nilsson and Jost (2020) recently argued that prior evidence based on Conway et al's (2018) LWA scale was due to its overlap with liberal ideology, and thus it did not provide empirical evidence of liberal authoritarianism. ${ }^{16}$ The issue raised by this critique is important. What

\footnotetext{
${ }^{16}$ Nilsson and Jost (2020) recommend solving this problem by using a different scale they claim is more "value neutral": Dunwoody and Funke's Aggression-Submission-Conventionalism (2016) scale. This recommendation is curious because Dunwoody and Funke's (2016) scale is highly unlikely to be value-
} 
do more focused empirical tests - tests based in long-accepted scientific practice -

reveal? Our multi-method evidence here suggests that, in fact, the scale is measuring something beyond mere liberalism. Almost all key effects across Studies 3-10 remain when controlling for political ideology. Further, in a similar fashion, almost all key effects remain within-liberals: Thus, when comparing liberal authoritarians to liberal nonauthoritarians, high-LWA persons show conceptually-expected correlations. As a result, the scale differentiates one kind of liberal from another kind, and thus cannot be reduced to mere ideology.

This array of evidence overwhelmingly suggests that, contrary to critics' claims, there is something beyond mere ideology captured by the LWA scale. What is that something beyond? Consistent with a long line of research on RWA, by far the most parsimonious answer to that question is that the something beyond is authoritarianism. And indeed, using standard content validity approaches also used in other authoritarianism work (e.g., Funke, 2005; Dunwoody \& Funke, 2016), Study 2 showed that participants evaluate the items in Conway's LWA scale as measurements of authoritarianism. This strong empirical evidence is echoed in the judgments of researchers Fasce and Avendaño (2020, p. 3), who commented that the items on Conway et al's LWA scale "are not merely statements of liberal ideology; they univocally reflect an extremely authoritarian attitude, opposed to liberal commitments such as equality

neutral, as evidenced by the fact that it is extremely highly correlated with Altemeyer's RWA scale (which those authors acknowledge is clearly not value-neutral) or scales based on Altemeyer's scale: One early version of the ASC scale correlated at $r=.81$ with Altemeyer's RWA scale, and the final ASC correlated at .71 and .73 in two samples with an RWA scale (Funke, 2005) based off of Altemeyer's scale (for details, see Dunwoody \& Funke, 2016). At a minimum, far more work needs to be done to establish a genuinely value-neutral scale where participants are not imagining conservative leaders as they complete the scale. And that work has to be placed against the large range of work described here, where efforts were made to produce a genuinely balanced approach to the LWA/RWA question using standard social psychological methods. 
among citizens, freedom of expression, and tolerance toward political and cultural diversity."

Taken together, this array of triangulating evidence points to the conclusion that as is the case for the scientific consensus on the Altemeyer RWA scale on which it was based - Conway et al's LWA scale is a valid measurement of authoritarianism.

LWA helps unconfound ideology from authoritarianism. In commenting on the LWA scale, Nilsson and Jost (2020) argued that "they [Conway et al, 2018] deliberately confounded authoritarian inclinations and support for liberal (as opposed to conservative) opinions and groups in society." The present work helps illustrate that this criticism is misguided. As laid out in Conway et al's (2018) original LWA paper, they did indeed deliberately include parallel ideological content in their LWA scale. However, as they noted, they were not trying to deliberately confound ideology and authoritarianism, but deliberately trying to unconfound them. Indeed, Conway et al (2018) were attempting (and, as our work here across all studies supports, succeeding) to help solve the very problem those authors critical of LWA themselves recently raised with Altemeyer's RWA scale (from Nilsson \& Jost, 2020):

“For example, Altemeyer's RWA scale contains items such as 'You have to admire those who challenged the law and the majority's view by protesting for women's abortion rights, for animal rights, or to abolish school prayer' (reversescored) and 'God's laws about abortion, pornography and marriage must be strictly followed before it is too late, and those who break them must be strongly punished'. These items conflate authoritarian attitudes with conservative positions on specific issues, such as women's rights, abortion, and marriage 
equality. This content overlap could produce a spurious correlation between authoritarianism and conservatism."

We agree. As we have laid out here, among the ways to try and better understand authoritarianism distinct from ideology is to produce equivalent parallel scales that use similar authoritarian language on both sides of the ideological spectrum. Conway et al (2018)'s scale - unlike Altemeyer's early LWA scale - used language that created straightforward equivalence across the scales. While no endeavor is perfect - and the nature of the task means it is impossible to produce exactly comparable scales (by definition, a left-wing authoritarian scale contains left-wing content, and a right-wing authoritarianism scale contains right-wing content) - nonetheless, the overwhelming amount of empirical evidence presented in Studies 2-11 suggests Conway et al's (2018) LWA scale is a valid measurement of liberal authoritarianism. Further, this evidence has to be taken in context with other evidence showing the predictive validity of Conway et al's LWA scale for (1) voting intentions in the 2016 election (Conway \& McFarland, 2019), (2) informational contamination, reactance, and support for divisive behaviors (Conway et al., in press), and (3) a reactive stance against reward for application (Fasce \& Avendaño, 2020).

Importantly, this approach has import not just for our understanding of left-wing authoritarianism, but also authoritarianism more generally. In fact, taken at face value, Nilsson and Jost's (2020) critique of Altemeyer calls into question decades of RWA research that has established the fundamentals of the authoritarian person that are now largely accepted as axiomatic by the field at large. Is it possible that all the research showing that, for example, authoritarians are threat sensitive really just means that 
conservatives are threat sensitive? If so, then we have learned nothing about authoritarianism. The present work helps provide a more complete picture by considering directly what an authoritarian on the other side of the political aisle might look like, thus helping us separate authoritarianism from ideology. When we do that, we see that authoritarianism on the left shares some similar properties with authoritarians on the right - for example, they both show heightened sensitivity to threat. As a result of this, we can more confidently isolate the effects of authoritarianism as an ideologically embedded theoretical construct.

\section{The Ideological Asymmetry Debate}

The present results further fit into a growing literature showing that negativelyvalenced outcomes once believed to asymmetrically apply to conservatives can in fact sometimes apply to liberals as well (e.g., Clark \& Winegard, 2020; Crawford, 2017; Ditto et al., 2019; Duarte et al., 2015; Eadeh \& Chang, 2019; Fiagbenu et al., 2019; Frimer et al., 2017; Honeycutt \& Jussim, 2020; Jussim et al., 2015; Jussim et al., 2016; Proch et al., 2018). For example, Fiagbenu and colleagues (2019) recently showed that, while in line with traditional asymmetrical conceptions of ideology, conservatives showed more learning of negative stimuli in a "BeanFest" game, liberals actually showed more learning of negative stimuli when the same scenario was re-framed as a "StockFest" game. Similarly, work reveals that in some circumstances, liberals (versus conservatives) can show less acceptance of attitudinal ambivalence (Newman \& Sargent, 2020; Sargent \& Newman, 2020), more desire for social stability (Proch et al., 2018), less cognitive complexity (Conway et al., 2016; Houck \& Conway, 2019), more dogmatism (Conway et 
al., 2016), more negative outgroup attitudes (Chambers et al., 2013), and more ingroup bias (Ditto et al., 2019).

The present results directly contribute to that debate by demonstrating that authoritarianism - once largely confined to the right side of the political spectrum - can also be found in general populations on the left side of the political spectrum. However, we must be cautious in over-interpreting this as perfect evidence of authoritarian symmetry, whereby we assume that liberals and conservatives are essentially equal with respect to authoritarianism. Indeed, there are at least three interpretations which we do not make.

First, we are not claiming that there are equal numbers of authoritarians among both liberals and conservatives. At this point, we simply do not have enough data to know the answer to that question for certain - but we agree with Jost et al. (2003) that there are reasons to expect authoritarianism to appear more frequently on the right than on the left. As a result, in claiming that there are a large number of measurable left-wing authoritarians world-wide, we are not claiming that they are of an equal number as rightwing authoritarians. We do not know for sure, but we rather suspect that conservative authoritarians will remain more prominent worldwide for much the same reasons detailed by Jost et al. (2003) - and although our own data suggest plenty of evidence of LWA, they also suggest a small (but real) tendency for RWA to be more prominent.

Second, we do not mean that specific authoritarians on the left and the right will be identical in every respect. Indeed, that would be highly improbable given the differences in liberals and conservatives more broadly. Rather, our data suggests that leftwing authoritarians share the basic properties of an authoritarian person, and as such are 
similar to right-wing authoritarians in those properties. Thus, it is reasonable to call someone scoring high on the LWA scale an "authoritarian" in the same way that it is reasonable to call someone scoring high on the RWA scale an "authoritarian." However, we would expect them to be different in multiple ways too, and parsing out those similarities and differences is an important task for future research (Chan et al., 2018). To name just one potential example, Conway et al. (2020) note that in the U.S., a liberal authoritarian may feel that authoritarianism is less congruent with ingroup norms about the topic than a conservative authoritarian. Thus, a liberal authoritarian in the U.S. may be analogous to an introvert living in a house of extraverts, while a conservative authoritarian may be like an introvert living in a house of introverts. Both persons are comparably equally introverted (or authoritarian), and yet those two people should differ on measurable qualities as well.

Finally, we also must be careful to not present this debate as a false dichotomy between perfect symmetry and validity. As we have outlined, there almost certainly will be some asymmetry between LWA and RWA, either in the frequencies those persons occur, their psychological properties, or both. However, these asymmetries do not undermine the larger empirical validity and theoretical relevance of the LWA construct. Because one can identify state-or-trait asymmetries between two introverts does not mean either of them is not introverted. That is a separate question that is dependent on the specific properties of the introvert. As we have shown in Studies 1-12, there is ample evidence to believe that authoritarians exist on the left side of the political spectrum just as they do on the right side.

\section{Limitations}


Like all studies, the present study has limitations. First, although employing much larger and more diverse samples than most previous work on authoritarianism, Studies 111 (like much prior authoritarianism research) are nonetheless limited to the United States and should not be taken to generalize beyond that region.

Further, as other researchers have noted (Nilsson et al., 2020), the Conway et al (2018) scale on which Studies 2-11 are based is not perfect. However, essentially all critiques of individual items on the scale hinge on the argument that these items do not measure anything beyond left-wing ideology. ${ }^{17}$ As such, all these smaller critiques are best addressed with triangulating empirical evidence that the whole collection of items used in the way originally intended by the authors of the scale, as a total summative measure - is in fact capturing something beyond mere ideology. Evidence that the whole scale is valid suggests at a minimum that the collection of items as a whole is valid - and thus directly suggests there is no systemic problem with items interfering with the validity of the scale. It is just that kind of whole-scale validity evidence that has been supplied across multiple studies in the present package. This empirical approach mirrors the approach in other domains when critiques arise of the empirical validity of particular theoretical constructs (e.g., Banaji et al., 2004).

However, we acknowledge that Conway et al's (2018) LWA scale, like all scales, is not perfect. The LWA scale does of course have room for improvement (Conway, 2020). But saying a scale is imperfect is not the same as saying a scale is invalid. All measurements contain imperfections and all studies contain messiness, and yet that

\footnotetext{
${ }^{17}$ We pause to note that, if this were true, as a measurement of liberalism the LWA scale would paint an excessively unflattering portrait of liberals - a portrait that would go against much theorizing about liberalism. Fortunately, our own data suggest this is not true, and thus the scale can rather be viewed as a measurement of a particular kind of liberal, and not a more general measurement of liberalism.
} 
should not deter us from bigger-picture research conclusions (Cooper, 2016). Thus, we acknowledge the facts that (a) like virtually every scale, the LWA scale could be improved, and (b) as a scale designed to parallel the most widely-used RWA scale, it inherited some of that scale's weaknesses. However, this lack of perfection should not be confused with the larger, big-picture issue of the degree that it can be construed as a valid measurement of left-wing authoritarianism. The overwhelming amount of evidence across multiple studies speaks clearly: It can be accurately viewed as a measurement of left-wing authoritarianism.

\section{Concluding Thoughts}

Recent evidence has revealed a need for balanced evaluations of potential symmetries and asymmetries related to political ideology (e.g., Clark \& Winegard, 2020; Crawford, 2017; Ditto et al., 2019; Duarte et al., 2015; Eadeh \& Chang, 2019; Fiagbenu et al., 2019; Frimer et al., 2017; Honeycutt \& Jussim, 2020; Jussim et al., 2015; Jussim et al., 2016; Proch et al., 2018). Using a multi-method approach spanning multiple content areas, validity types, statistical controls, and scale types, the present results consistently show that, just as right-wing persons are sometimes authoritarian, left-wing persons may also be similarly authoritarian. Taken together, this large array of evidence suggests that left-wing authoritarianism is more of a reality than a myth. 


\section{References}

Altemeyer, R. A. (1996). The Authoritarian Spectre. Harvard University Press.

Altemeyer, B. (1998). The other "authoritarian" personality. Advances in Experimental Social Psychology, 30, 47-91. http://dx.doi.org/10.1027/1614-0001.27.3.117

Ariely, G., \& Davidov, E. (2010). Can we rate public support for democracy in comparable way? Cross-national equivalence of democratic attitudes in the world value survey. Social Indicators Research, 104(2), 271-86.

Banaji, M. R., Nosek, B. A., \& Greenwald, A. G. (2004). No place for nostalgia in science: A response to Arkes and Tetlock. Psychological Inquiry, 15(4), 279-310. https://www.jstor.org/stable/20447240

Bates, D., Maechler, M., Bolker, B., \& Walker, S. (2015). Fitting linear mixed effects models using lme4. Journal of Statistical Software, 67(1), 148. https://doi.org/10.18637/jss.v067.i01.

Baumeister, R. F. (1993). Self-Esteem: The Puzzle of Low Self-Regard. Plenum Press.

Beall, A. T., Hofer, M. K., \& Schaller, M. (2016). Infections and elections: Did an Ebola outbreak influence the 2014 U.S. Federal Elections (and if so, how?). Psychological Science, 27(5), 595-605. https://doi.org/10.1177/0956797616628861

Breiman, L., \& Freedman, D. (1983). How many variables should be entered in a regression equation? Journal of the American Statistical Association, 78(381), 131-136. https://doi.org/10.1080\%2F01621459.1983.10477941

Chambers, J.R., Schlenker, B.R., \& Collisson, B. (2013). Ideology and prejudice: The role of value conflicts. Psychological Science, 24(2), 140-149. 
https://doi.org/10.1177/0956797612447820

Choma, B. L., \& Hanoch, Y. (2017). Cognitive ability and authoritarianism: Understanding support for Trump and Clinton. Personality and Individual Differences, 106, 287-291. https://doi.org/10.1016/j.paid.2016.10.054

Choma, B. L., \& Hodson, G. (2017). Right-wing ideology: Positive (and negative) relations to threat. Social cognition, 35(4), 415-432.

Clark, C. J., \& Winegard, B. M. (2020). Tribalism in war and peace: The nature and evolution of ideological epistemology and its significance for modern social science. Psychological Inquiry, 31(1), 1-22.

https://doi.org/10.1080\%2F1047840x.2020.1721233

Clifford, S., Jewell, R. M., \& Waggoner, P. D. (2015). Are samples drawn from Mechanical Turk valid for research on political ideology? Research and Politics, 2(4), 1-9. https://doi.org/10.1177/2053168015622072

Chan, L., McFarland, J. D., \& Conway, L. G., III. (2018). Political contamination of social psychology: A review of Crawford and Jussim's (2017) edited book 'The politics of social psychology.' Social Justice Research, 31(3), 323-333. https://doi.org/10.1007/s11211-018-0312-y

Conway, L. G., III. (2020, February 27-29). Is left-wing authoritarianism real?: Evidence on both sides of the debate [Symposium]. Society for Personality and Social Psychology, New Orleans, LA, United States.

Conway, L. G., III, Bongard, K., Plaut, V. C., Gornick, L. J., Dodds, D., Giresi, T., Tweed, R. G., Repke, M. A., \& Houck, S. C. (2017). Ecological origins of freedom: Pathogens, heat stress, and frontier topography predict more vertical but 
less horizontal governmental restriction. Personality and Social Psychology Bulletin, 43(10), 1378-1398. https://doi.org/10.1177/0146167217713192

Conway, L. G., III, Clements, S. M., \& Tweed, R. G. (2006). Collectivism and governmentally initiated restrictions: A cross-sectional and longitudinal analysis across nations and within a nation. Journal of Cross-Cultural Psychology, 37(1), 1-23. https://doi.org/10.1177/0022022105282293

Conway, L. G., III, Conway, K. R., Gornick, L. J., \& Houck, S. C. (2014). Automated integrative complexity. Political Psychology, 35(5), 603-624. https://doi.org/10.1111/pops.12209

Conway, L. G. III, Dodds, D., Towgood, K. H., McClure, S, \& Olson, J. (2011). The biological roots of complex thinking: Are heritable attitudes more complex? Journal of Personality, 79(1), 101-134. https://doi.org/10.1111/j.14676494.2010.00690.x

Conway, L. G., III, Gornick, L. J., Burfiend, C., Mandella, P., Kuenzli, A., Houck, S. C., \& Fullerton, D. T. (2012). Does simple rhetoric win elections? An integrative complexity analysis of U.S. presidential campaigns. Political Psychology, 33(5), 599-618. https://doi.org/10.1111/j.1467-9221.2012.00910.x

Conway, L. G. III, Gornick, L. J., Houck, S. C., Anderson, C., Stockert, J., Sessoms, D., \& McCue, K. (2016). Are conservatives really more simple- minded than liberals? The domain specificity of complex thinking. Political Psychology, 37(6), 777-798. https://doi.org/10.1111/pops.12304

Conway, L. G, III, Houck, S. C., Chan, L., Repke, M. A., \& McFarland, J. (in press). The 
agreement paradox: How pressures for agreement can ultimately divide us. In J.W. van Prooijen (Ed.), Current Issues in Social Psychology: Political Polarization. New York: Routledge.

Conway, L. G., III, Houck, S. C., Gornick, L. J., \& Repke, M. A. (2016). Ideologicallymotivated perceptions of complexity: Believing those who agree with you are more complex than they are. Journal of Language and Social Psychology, 35(6), 708-718. https://doi.org/10.1177/0261927x16634370

Conway, L. G., III, Houck, S. C., Gornick, L. J., Repke, M. R. (2018). Finding the Loch Ness Monster: Left-Wing Authoritarianism in the United States. Political Psychology, 39(5), 1049-1067. https://doi.org/10.1111/pops.12470

Conway, L. G., III, \& McFarland, J. D. (2018). Do Right-Wing and Left-Wing Authoritarianism Predict Election Outcomes?: Support for Obama and Trump Across Two United States Presidential Elections. Personality and Individual Differences, 138, 84-87. https://doi.org/10.1016/j.paid.2018.09.033

Conway, L. G., III, McFarland, J. D., Costello, T. H., \& Lilienfeld, S. O. (2020). The curious case of left-wing authoritarianism: When authoritarian persons meet antiauthoritarian norms [Manuscript Under Review]. Department of Psychology, University of Montana.

Conway, L. G., III, Repke, M. A., \& Houck, S. C. (2017). Donald Trump as a cultural revolt against perceived communication restriction: Priming political correctness norms causes more Trump support. Journal of Social and Political Psychology, 5(1), 244-259. https://doi.org/10.5964/jspp.v5i1.732

Conway, L. G. III, Salcido, A., Gornick, L. J., Bongard, K. A., Moran, M., \& Burfiend, 
C. (2009). When self-censorship norms backfire: The manufacturing of positive communication and its ironic consequences for the perceptions of groups. Basic and Applied Social Psychology, 31(4), 335-

347.https://doi.org/10.1080/01973530903317169

Conway, L. G., III, \& Schaller, M. (2005). When authority's commands backfire: Attributions about consensus and effects on deviant decision making. Journal of Personality and Social Psychology, 89(3), 311-326. https://doi.org/10.1037/00223514.89.3.311

Conway, L. G., III, \& Schaller, M. (2007). How communication shapes culture. In K. Fiedler (Ed.), Frontiers of Social Psychology: Social communication (pp. 107127). Psychology Press.

Conway, L. G., III, Suedfeld, P., \& Tetlock, P. E. (2018). Integrative complexity in politics. In A. Mintz (Ed.), Oxford Handbook of Behavioral Political Science. Oxford: Oxford University Press. https://doi.org/10.1093/oxfordhb/9780190634131.013.7

Conway, L. G., III., Thoemmes, F., Allison, A. M., Hands Towgood, K., Wagner, M. J., Davey, K., Salcido, A., Stovall, A. N., Dodds, D. P., Bongard, K, \& Conway, K. R. (2008). Two ways to be complex and why they matter: Implications for attitude strength and lying. Journal of Personality and Social Psychology, 95(5), 1029-1044. https://doi.org/10.1037/a0013336

Conway, L. G., III, Woodard, S. R., \& Zubrod, A. (2020). Social psychological 
measurements of COVID-19: Coronavirus perceived threat, government response, impacts, and experiences questionnaires. PsyArXiv. https://doi.org/10.31234/osf.io/z2x9a

Conway, L. G., III, Woodard, S. R., \& Zubrod, A., \& Chan, L. Why are conservatives less concerned about the coronavirus (COVID-19) than liberals? PsyArXiv https://psyarxiv.com/fgb84/

Conway, L. G., III, Zubrod, A., \& Chan, L. (2020). The paradox of the tribal equalitarian. Psychological Inquiry, 31(1), 48-52. https://doi.org/10.1080\%2F1047840x.2020.1722018

Cooper, M. L. (2016). Personality processes and individual differences. Journal of Personality and Social Psychology, 110(3), 431-434. https://www.apa.org/pubs/journals/features/psp-p0000033.pdf

Costello, T. H., Bowes, S. M., Stevens, S. T., Waldman, I. D., \& Lilienfeld, S. O. (2020). Clarifying the structure and nature of left-wing authoritarianism. PsyArXiv. https://doi.org/10.31234/osf.io/3nprq

Crawford, J. T. (2017). Are conservatives more sensitive to threat than liberals? It depends on how we define threat and conservatism. Social Cognition, 35(4), 354373. https://doi.org/10.1521/soco.2017.35.4.354 https://doi.org/10.1177/0146167207303949

De Regt, S., Mortelmans, D., \& Smits, T. (2011). Left-wing authoritarianism is not a myth, but worrisome reality: Evidence from 13 Eastern European countries. Communist and Post-Communist Studies, 44(4), 299-308. https://doi.org/10.1016/j.postcomstud.2011.10.006 
Diamant, J. (2018). Blacks more likely than others in U.S. to read the Bible regularly, see it as God's word. Pew Research Center. https://www.pewresearch.org/fact$\operatorname{tank/2018/05/07/blacks-more-likely-than-others-in-u-s-to-read-the-bible-~}$ regularly-see-it-as-gods-word/

Ditto, P., Liu, B., Clark, C. J., Wojcik, S., Chen, E., Grady, R. H., Celniker, J. B., \& Zinger, J. (2019). At least bias Is bipartisan: A meta-analytic comparison of partisan bias in liberals and conservatives. Perspectives on Psychological Science, 14(2), 273-291. https://doi.org/10.1177/1745691617746796

Donnellan, M. B., Oswald, F. L., Baird, B. M., \& Lucas, R. E. (2006). The miniIPIP scales: tiny-yet-effective measures of the Big Five factors of personality. Psychological Assessment, 18(2), 192-203. https://doi.org/10.1037/10403590.18.2.192

Duckitt, J. (2001). A dual-process cognitive-motivational theory of ideology and prejudice. In M. P. Zanna (Ed.), Advances in experimental social psychology, (Vol. 33, p. 41-113). Academic Press.

Duckitt, J. (2013). Introduction to the special section on authoritarianism in societal context: The role of threat. International Journal of Psychology, 48(1), 1-5. doi:http://dx.doi.org.weblib.lib.umt.edu:8080/10.1080/00207594.2012.738298

Duckitt, J., Bizumic, B., Krauss, S. W., Heled, E. (2010). A tripartite approach to rightwing authoritarianism: The authoritarianism-conservatism-traditionalism model Political Psychology, 31(5), 685-715. https://doi.org/10.1111/j.14679221.2010.00781.x

Duckitt, J., Wagner, C., du Plessis, I., \& Birum, I. (2002). The psychological bases of 
ideology and prejudice: Testing a dual process model. Journal of Personality and Social Psychology, 83(1), 75-93. https://doi.org/10.1037/0022-3514.83.1.75

Duarte, J. L., Crawford, J. T., Stern, C., Haidt, J., Jussim, L., \& Tetlock, P. E. (2015). Political diversity will improve social psychological science. Behavioral and Brain Sciences, 38. https://doi.org/10.1017\%2Fs0140525x14000430

Dunwoody, P. T., \& Funke, F. (2016). The Aggression-Submission-Conventionalism Scale: Testing a new three factor measure of authoritarianism. Journal of Social and Political Psychology, 4(2), 571-600. https://doi.org/10.5964\%2Fjspp.v4i2.168

Dyrbye, L., Herrin, J., West, C.P., et al. (2019). Association of racial bias with burnout among resident physicians. Journal of American Medical Association Network Open, 2(7). https://doi.org/10.1001/jamanetworkopen.2019.7457

Eadeh, F. R., \& Chang, K. K. (2019). Can threat increase support for liberalism? New insights into the relationship between threat and political attitudes. Social Psychological and Personality Science, 11(1), 88-96. https://doi.org/10.31234\%2Fosf.io\%2Fcz35s

Eysenck, H. J. (1954). Psychology of Politics. Routledge \& Kegan Paul.

Fasce, A., \& Avendaño, D. (2020). Opening the can of worms: A comprehensive examination of authoritarianism. Personality and Individual Differences, 163, 1-9. https://doi.org/10.1016/j.paid.2020.110057

Federico, C. M., Fisher, E. L., \& Deason, G. (2017). The authoritarian left withdraws 
from politics: Ideological asymmetry in the relationship between authoritarianism and political engagement. Journal of Politics, 79(3), 1010-1023. https://doi.org/10.1086/692126

Feldman, S. (2001). Authoritarianism. In N. J. Smelser \& P. B. Baltes (Eds.), International encyclopedia of the social \& behavioral sciences (p. 971). Elsevier.

Feldman, S. (2003). Enforcing social conformity: A theory of authoritarianism. Political Psychology, 24(1), 41-74. https://doi.org/10.1111/0162-895X.00316

Fiagbenu, M. E., Proch, J., \& Kessler, T. (2019). Of deadly beans and risky stocks: Political ideology and attitude formation via exploration depend on the nature of the attitude stimuli. British Journal of Psychology. https://doi.org/10.1111/bjop.12430

Fincher, C. L., \& Thornhill, R. (2012). Parasite-stress promotes in-group assortative sociality: The cases of strong family ties and heightened religiosity. Behavioral and Brain Sciences, 35(2), 61-79. https://doi.org/10.1017\%2Fs0140525x11000021

Frimer, J. A., Gaucher, D., \& Schaefer, N. K. (2014). Political conservatives' affinity for obedience to authority is loyal, not blind. Personality and Social Psychology Bulletin, 4O(9), 1205-1214. https://doi.org/10.1177\%2F0146167214538672

Frimer, J., Skitka, L. J., \& Motyl, M. (2017). Liberals and conservatives are similarly motivated to avoid exposure to one another's opinions. Journal of Experimental Social Psychology, 72, 1-12. https://doi.org/10.1016/j.jesp.2017.04.003

Funke, F. (2005). The dimensionality of right-wing authoritarianism: Lessons from the dilemma between theory and measurement. Political Psychology, 26(2), 195-218. 
https://doi.org/10.1111/j.1467-9221.2005.00415.x

Hayes, A. F. (2017). Introduction to mediation, moderation, and conditional process analysis: A regression-based approach. Guilford publications.

Hayes, A. F., \& Rockwood, N. J. (2020). Conditional process analysis: Concepts, computation, and advances in the modeling of the contingencies of mechanisms. American Behavioral Scientist, 64(1), 19-54. https://doi.org/10.1177/0002764219859633

Henrich, J., Heine, S. J., \& Norenzayan, A. (2010). The weirdest people in the world?. Behavioral and Brain Sciences, 33(2-3), 61-83. https://doi.org/10.2139/ssrn.1601785

Honeycutt, N., \& Jussim, L. (2020). A model of political bias in social science research. Psychological Inquiry, 31(1), 73-85. https://doi.org/10.1080/1047840x.2020.1722600

Houck, S. C., \& Conway, L. G. III. (2019). Strategic communication and the integrative complexity-ideology relationship: Meta-analytic findings reveal differences between public politicians and private citizens in their use of simple rhetoric. Political Psychology, 40(5), 1119-1141. https://doi.org/10.1111/pops.12583

Houck, S. C., Conway, L. G., III, \& Gornick, L. J. (2014). Automated integrative complexity: Current challenges and future directions. Political Psychology, 35(5), 647-659. https://doi.org/10.1111/pops.12209

Houck, S. C., Conway, L. G., III, \& Repke, M. (2014). Personal closeness and perceived torture efficacy: If torture will save someone I'm close to, then it must work. 
Peace and Conflict: Journal of Peace Psychology, 20(4), 590-592. https://doi.org/10.1037/pac0000058

Houck, S. C., Conway, L. G. III, Parrow, K., \& Luce, A., \& Salvati, J. (2018). An integrative complexity analysis of religious and irreligious thinking. Sage Open, 8(3),1-12. https://doi.org/10.1177/2158244018796302

Houck, S. C., Repke, M. A., \& Conway, L. G., III. (2017). Understanding what makes terrorist groups' propaganda effective: An integrative complexity analysis of ISIL and Al Qaeda. Journal of Policing, Intelligence and Counter Terrorism, 12(2), 105-118. https://doi.org/10.1080/18335330.2017.1351032

INSOL. (2020). Eastern European Countries: Committee Introduction and Members. https://www.insol-europe.org/eastern-european-countries-committee-introductionand-members\#: :text=Thanks $\% 20$ to $\% 20$ the $\% 20$ existence $\% 20$ of,Serbia $\% 2 \mathrm{C} \% 20$ Slovak\%20Republic\%20and\%20Slovenia.

Inglehart, R., C. Haerpfer, A. Moreno, C. Welzel, K. Kizilova, J. Diez-Medrano, M. Lagos, P. Norris, E. Ponarin \& B. Puranen et al. (Eds.). 2014. World Values Survey: Round Six - Country-Pooled Datafile Version: https://www.worldvaluessurvey.org/WVSDocumentationWV6.jsp. Madrid: JD Systems Institute.

Jost, J. T., Nosek, B. A., \& Gosling, S. D. (2008). Ideology: Its resurgence in social, personality, and political psychology. Perspectives on Psychological Science, 3(2), 126-136. https://doi.org/10.1111/j.1745-6916.2008.00070.x 
Jost, T., Glaser, J., Kruglanski, A. W., \& Sulloway, F. J. (2003). Political conservatism as motivated social cognition. Psychological Bulletin 129(3), 339-375. https://doi.org/10.4324/9781315175867-5

Jussim, L., Crawford, J.T., Stevens, S. T., \& Anglin, S. M (2016). The politics of social psychological science: Distortions in the social psychology of intergroup relations. Social psychology of political polarization (P. Valdesolo, and J. Graham, eds, pp. 165-196). Routledge.

Jussim, L., Crawford, J.T., Anglin, S. M., \& Stevens, S. T. (2015). Ideological bias in social psychological research. In J. Forgas, W. Crano, \& K. Fiedler (Eds.), Social Psychology and Politics (pp. 91-109). Taylor \& Francis.

Karwowski, M., Kowal, M., Groyecka, A., Bialek, M., Lebuda, I., Sorokowska, A., \& Sorokowski, P. (2020). When in danger, turn right: Does Covid-19 threat promote social conservatism and right-wing presidential candidates? Human Ethology, 35(1), 37-48. https://doi.org/10.22330/he/35/037-048

Kennedy, R., Clifford, S., Burleigh, T., Jewell, R., \& Waggoner, P. (2018). The shape of and solutions to the MTurk quality crisis. Political Science Research and Methods, 8(4), 614-629. https://doi.org/10.2139/ssrn.3272468

Kitayama, S., Conway, L. G., III, Pietromonaco, P.R., Park, H., \& Plaut, V. C. (2010). Ethos of independence across regions in the United States: The productionadoption model of cultural change. American Psychologist, 65(6), 559-574. https://doi.org/10.1037/a0020277

Kitayama, S., Ishii, K., Imada, T., Takemura, K., \& Ramaswamy, J. (2006). Voluntary 
settlement and the spirit of independence: Evidence from Japan's “northern frontier". Journal of Personality and Social Psychology, 91(3), 369-384. https://doi.org/10.1037/0022-3514.91.3.369

Lorah, J. (2018). Effect size measures for multilevel models: definition, interpretation, and TIMSS example. Large-Scale Assessments in Education, 6, 8, https://doi.org/10.1186/s40536-018-0061-2

Ludeke, S. G., Klitgaard, C. N., \& Vitriol, J. (2018). Comprehensively-measured authoritarianism does predict vote choice: The importance of authoritarianism's facets, ideological sorting, and the particular candidate. Personality and Individual Differences, 123, 209-216. https://doi.org/10.1016/j.paid.2017.11.019

Malka, A., Lelkes, Y., Bakker, B. N., \& Spivack, E. (2020). Who is open to authoritarian governance within western democracies? Perspectives on Politics, 1-20. https://doi.org/10.1017/s1537592720002091

Malka, A., Lelkes, Y., \& Soto, C. J. (2017). Are cultural and economic conservatism positively correlated? A large-scale cross-national test. British Journal of Political Science, 49(3), 1045-1069. https://doi.org/10.1017/s0007123417000072

Malka, A., Lelkes, Y., \& Holzer, N. (2017). Rethinking the rigidity of the right model: Three suboptimal methodological practices and their implications. In J. T. Crawford, \& L. Jussim (Eds.) Frontiers of social psychology: Politics of social psychology (pp. 116-135). Psychology Press.

Manson, J. H. (2020). Right-wing Authoritarianism, Left-wing Authoritarianism, and pandemic-mitigation authoritarianism. Personality and individual differences, 167, 110251.

McConahay, J. B. (1986). Modern racism, ambivalence, and the modern racism scale. In 
J. F. Dovidio \& S. L. Gaertner (Eds.), Prejudice, discrimination and racism (pp. 91-126). Academic Press.

McFarland, S.G., Ageyev, V.S., Abalakina-Paap, M.A. (1992). Authoritarianism in the former Soviet Union. Journal of Personality and Social Psychology, 63(6), 10041010. https://doi.org/10.1037/0022-3514.63.6.1004

McFarland, S.G., Ageyev, V.S., Abalakina-Paap, M.A. (1993). The authoritarian personality in the United States and the former Soviet Union: Comparative studies. In W.F. Stone, G. Lederer, R. Christie(Eds.), Strength and Weakness: The Authoritarian Personality Today (pp. 199-225). Springler Verlag.

McFarland, S. G., Ageyev, V. S., \& Djintcharadze, N. (1996). Russian authoritarianism two years after communism. Personality and Social Psychology Bulletin, 22(2), 210-217. https://doi.org/10.1177/0146167296222010

Miller, S. V. (2017). Economic threats or societal turmoil? Understanding p References for authoritarian political systems. Political Behavior, 39(2), 457-78. https://doi.org/10.1007/s11109-016-9363-7

Mullen, E., Bauman, C. W., \& Skitka, L. J. (2003). Avoiding the pitfalls of politicized psychology. Analyses of Social Issues and Public Policy, 3(1), 171-176. https://doi.org/10.1111/j.1530-2415.2003.00021.x

Murray, D. R., \& Schaller, M. (2010). Historical prevalence of infectious diseases within 230 geopolitical regions: A tool for investigating origins of culture. Journal of Cross-Cultural Psychology, 41(1), 99-108. doi:10.1177/0022022109349510

Napier, J. L., \& Jost, J. T. (2008). The "antidemocratic personality" revisited: A crossnational investigation of working-class authoritarianism. Journal of Social 
Issues, 64(3), 595-617. https://doi.org/10.1002/9781444307337.ch9

Newman, L. S., \& Sargent, R. H. (2020). Liberals Report Lower Levels of Attitudinal Ambivalence Than Conservatives. Social Psychological and Personality Science. https://doi.org/10.1177/1948550620939798

Newport, F. (2019). Americans' views of Israel remain tied to religious beliefs. Gallup. https://news.gallup.com/opinion/polling-matters/247937/americans-views-israelremain-tied-religious-beliefs.aspx

Nilsson, A., \& Jost, J. T. (2020). The authoritarian-conservatism nexus. Current Opinion in Behavioral Sciences, 34, 148-154. https://doi.org/10.1016/j.cobeha.2020.03.003

Nosek, B. A. (2005). Moderators of the relationship between implicit and explicit evaluation. Journal of Experimental Psychology: General, 134(4), 565-584. https://doi.org/10.1037/0096-3445.134.4.565

Oishi, S., Yagi, A., Komiya, A., Kohlbacher, F., Kusumi, T., \& Ishii, K. (2017). Does a major earthquake change job preferences and human values? European Journal of Personality, 31(3), 258-265. https://doi.org/10.1002\%2Fper.2102

Pentony, J.F., Peterson, K.S.E., Philips, O., Leong, C., Harper, P., Bakowski, A., Steward, S., Gonzales, R. (2000). A comparison of authoritarianism in the United States, England, and Hungary with selected nonrandom samples. European Psychologist, 5(4), 259-268. https://doi.org/10.1027//1016-9040.5.4.259

Preacher, K. J. (2015). Advances in mediation analysis: A survey and synthesis of new developments. Annual review of psychology, 66, 825-52.

Peterson, B. E., \& Gerstein, E. D. (2005). Fighting and flying: Archival analysis of threat, 
authoritarianism, and the North American comic book. Political Psychology, 26(6), 887-904. https://doi.org/10.1111\%2Fj.1467-9221.2005.00449.x

Proch, J., Elad-Strenger, J., \& Kessler, T. (2018). Liberalism and conservatism, for a change!: Rethinking the association between political orientation and relation to societal change. Political Psychology, 40(4), 877-903.

https://doi.org/10.1111/pops.12559

R Core Team. (2014). R: A language and environment for statistical computing (Computer software). R Foundation for Statistical Computing, Vienna, Austria. http://www.R-project.org/.

Ray, J. J. (1983). Half of all authoritarians are left-wing: A reply to Eysenck and Stone. Political Psychology, 4(1), 139-144. https://doi.org/10.2307/3791178

Rokeach, M. (1960). The open and closed mind: Investigations into the source of beliefs systems and personality systems. Basic Books.

Sargent, R. H., \& Newman, L. S. (2020). Conservatism and attitudinal ambivalence: Investigating conflicting findings. Personality and Individual Differences. https://doi.org/10.1016/j.paid.2020.109996

Saunders, B., Badaan, V., Hoffarth, M., \& Jost, J. (2020, February 27-29). Spotting the Loch Ness Monster, or smiling for the surgeon's photograph? A critique of Conway and colleagues' (2018) research on left-wing authoritarianism [Symposium]. Society for Personality and Social Psychology, New Orleans, LA, United States.

Schaller, M., Conway, L. G., III, \& Tanchuk, T. (2002). Selective pressures on the once 
and future contents of ethnic stereotypes: Effects of the 'communicability' of traits. Journal of Personality and Social Psychology, 82(6), 861-877. https://doi.org/10.1037/0022-3514.82.6.861

Shils, E. A. (1954). Authoritarianism: Right and left. In Christie, R., \& Jahoda, M. (Eds.),Studies in the Scope and the Method of the Authoritarian Personality (pp. 24-29). Free Press.

Sprong, S., Jetten, J., Wang, Z., Peters, K., Mols, F., Verkuyten, M., Bastian, B., Ariyanto, A., Autin, F., Ayub, N., Badea, C., Besta, T., Butera, F., Costa-Lopes, R., Cui, L., Fantini, C., Finchilescu, G., Gaertner, L., Gollwitzer, M., ... Wohl, M. J. A. (2019). “Our Country Needs a Strong Leader Right Now”: Economic Inequality Enhances the Wish for a Strong Leader. Psychological Science, 30(11), 1625-1637. https://doi.org/10.1177/0956797619875472

Stone, W. F. (1980). The myth of left-wing authoritarianism. Political Psychology, 2(3/4), 3-19. https://doi.org/10.2307/3790998

Terrizzi, J. A., Shook, N. J., \& McDaniel, M. A. (2013). The behavioral immune system and social conservatism: A meta-analysis. Evolution and Human Behavior, 34(2), 99-108. https://doi.org/10.1016\%2Fj.evolhumbehav.2012.10.003

Tetlock, P. E. (1994). Political psychology or politicized psychology: Is the road to scientific hell paved with good moral intentions? Political Psychology, 15(3), 509-529. https://doi.org/10.2307\%2F3791569

Tetlock, P. E., Armor, D., Peterson, R.S. (1994). The slavery debate in antebellum America: Cognitive style, value conflict, and the limits of compromise. Journal of 
Personality and Social Psychology, 66(1), 115-126. https://doi.org/10.1037/00223514.66.1.115

Thomas, K. R. (2013). Wild analysis in politics. Political Psychology, 34(6), 927-934. https://doi.org/10.1111/pops. 12090

Todosijević, B. (2005). Authoritarianism and socialist ideology: The case of Yugoslavia, 1995. In R.F. Farnen, H. De Dekker, C. Landtsheer, H. Sünker, D.B. German (Eds.), Democratization, Europeanization, and Globalization Trends: Crossnational Analysis of Authoritarianism, Socialization, Communications, Youth, and Social Policy. Peter Lang.

Todosijević, B., \& Enyedi, Z. (2008). Authoritarianism without dominant ideology: Political manifestations of authoritarian attitudes in Hungary. Political Psychology, 29(5), 767-787. https://doi.org/10.1111/j.1467-9221.2008.00663.x

Van de Vliert, E. (2013). Climato-economic habitats support patterns of human needs, stresses, and freedoms. Behavioral and Brain Sciences, 36(5), 465-480. https://doi.org/10.1017\%2Fs0140525x12002828

Van de Vliert, E., \& Conway, L. G. III. (2019). Northerners and Southerners differ in conflict culture. Negotiation and Conflict Management Research, 12(3), 256-277. DOI: $10.1111 / \mathrm{ncmr} .12138$.

Van Hiel, A., Duriez, B., Kossowska, M. (2006). The presence of left-wing authoritarianism in Western Europe and its relationship with conservative ideology. Political Psychology, 27(5), 769-793. https://doi.org/10.1111/j.14679221.2006.00532.x

Vasilopoulos, P., Marcus, G. E., \& Foucault, M. (2018). Emotional responses to the 
Charlie Hebdo Attacks: Addressing the authoritarianism puzzle. Political Psychology, 39(3), 557-575. https://doi.org/10.1111\%2Fpops.12439

Wronski, J. Bankert, A., Amira, K., Johnson, A.A., \& Levitan, L.C. (2018). A tale of two Democrats: How authoritarianism divides the Democratic Party. The Journal of Politics, 80(4), 1384-1388. https://doi.org/10.1086/699338

Zakrisson, I. (2005). Construction of a short version of the right-wing authoritarianism (RWA) scale. Personality and Individual Differences, 39, 863872. https://doi.org/10.1037\%2Ft26998-000 


\section{Appendix}

\section{LWA, LWA (De-Politicized), RWA, and Big 5 Items From Study 2}

\section{LWA Items:}

1. Our country desperately needs a mighty and liberal leader who will do what has to be done to destroy the radical traditional ways of doing things that are ruining us.

2. It's always better to trust the judgment of the proper authorities in science with respect to issues like global warming and evolution than to listen to the noisy rabble-rousers in our society who are trying to create doubts in people's minds.

3. The only way our country can get through the crisis ahead is to get rid of our "traditional" values, put some tough leaders in power who oppose those values, and silence the troublemakers spreading bad (and so-called "traditional") ideas.

4. Our country will be destroyed someday if we do not smash the traditional beliefs eating away at our national fiber and growing progressive beliefs.

5. Progressive ways and liberal values show the best way of life.

6. What our country really needs is a strong, determined leader who will crush the evil of pushy Christian religious people, and take us forward to our true path.

7. We should strongly punish those who try to uphold what they claim are "God's laws" about abortion, pornography, and marriage, when they break the actual laws of the country in order to do so.

8. There are many radical, immoral Christian people in our country today, who are trying to ruin it for their religious purposes, whom the authorities should put out of action.

9. Our country will be great if we honor the ways of progressive thinking, do what 
the best liberal authorities tell us to do, and get rid of the religious and conservative "rotten apples" who are ruining everything.

10. This country would work a lot better if certain groups of Christian troublemakers would just shut up and accept their group's proper place in society.

\section{$\underline{\text { LWA (De-Politicized) }}$}

1. Our country desperately needs a mighty and political leader who will do what has to be done to destroy the ways of doing things that are ruining us.

2. It's always better to trust the judgment of the proper authorities than to listen to the noisy rabble-rousers in our society who are trying to create doubts in people's minds.

3. The only way our country can get through the crisis ahead is to put some tough leaders in power who have the correct values and silence the troublemakers spreading bad ideas.

4. Our country will be destroyed someday if we do not smash the beliefs eating away at our national fiber.

5. Our group's ways and values show the best way of life.

6. What our country really needs is a strong, determined leader who will crush the evil of pushy people, and take us forward to our true path.

7. We should strongly punish those who try to uphold false rules, when they break the actual laws of the country in order to do so.

8. There are many radical, immoral people in our country today, who are trying to ruin it for their own purposes, whom the authorities should put out of action.

9. Our country will be great if we honor the ways of our group's thinking, do what 
the best authorities in our group tell us to do, and get rid of the other group's "rotten apples" who are ruining everything.

10. This country would work a lot better if certain groups of troublemakers would just shut up and accept their group's proper place in society.

\section{RWA Items:}

1. Our country desperately needs a mighty leader who will do what has to be done to destroy the radical new ways and sinfulness that are ruining us.

2. It's always better to trust the judgment of the proper authorities in government and religion than to listen to the noisy rabble-rousers in our society who are trying to create doubts in people's minds.

3. The only way our country can get through the crisis ahead is to get back to our traditional values, put some tough leaders in power, and silence the troublemakers spreading bad ideas.

4. Our country will be destroyed someday if we do not smash the perversions eating away at our moral fiber and traditional beliefs.

5. The "old-fashioned ways" and "old-fashioned values" still show the best way of life.

6. What our country really needs is a strong, determined leader who will crush evil, and take us back to our true path.

7. God's laws about abortion, pornography, and marriage must be strictly followed before it is too late, and those who break them must be strongly punished.

8. There are many radical, immoral people in our country today, who are trying to ruin it for their godless purposes, whom the authorities should put out of action. 
9. Our country will be great if we honor the ways of our forefathers, do what the authorities tell us to do, and get rid of the "rotten apples" who are ruining everything.

10. This country would work a lot better if certain groups of troublemakers would just shut up and accept their group's traditional place in society.

\section{$\underline{\text { Big } 5 \text { Items }}$}

1. I am the life of the party.

2. I sympathize with others' feelings.

3. I get chores done right away.

4. I have frequent mood swings.

5. I have a vivid imagination.

6. I talk to a lot of different people at parties.

7. I feel others' emotions.

8. I get upset easily.

9. I like order. 